\title{
Identification of Persistent and Resurgent Sodium Currents in Spiral Ganglion Neurons Cultured from the Mouse Cochlea
}

\author{
(D)Lorcan Browne, ${ }^{(D}$ Katie E. Smith, and ${ }^{\circledR}$ Daniel J. Jagger
}

DOI:http://dx.doi.org/10.1523/ENEURO.0303-17.2017

UCL Ear Institute, University College London, London WC1X 8EE, United Kingdom

\begin{abstract}
In spiral ganglion neurons (SGNs), the afferent single units of the auditory nerve, high spontaneous and evoked firing rates ensure preservation of the temporal code describing the key features of incoming sound. During postnatal development, the spatiotemporal distribution of ion channel subtypes contributes to the maturation of action potential generation in SGNs, and to their ability to generate spike patterns that follow rapidly changing inputs. Here we describe tetrodotoxin (TTX)-sensitive $\mathrm{Na}^{+}$currents in SGNs cultured from mice, whose properties may support this fast spiking behavior. A subthreshold persistent $\mathrm{Na}^{+}$current $\left(l_{\mathrm{NaP}}\right)$ and a resurgent $\mathrm{Na}^{+}$current $\left(l_{\mathrm{NaR}}\right)$ both emerged prior to the onset of hearing and became more prevalent as hearing matured. Nav $\beta 4$ subunits, which are proposed to play a key role in mediating $I_{\mathrm{NaR}}$ elsewhere in the nervous system, were immunolocalized to the first heminode where spikes are generated in the auditory nerve, and to perisomatic nodes of Ranvier. ATX-II, a sea anemone toxin that slows classical $\mathrm{Na}^{+}$channel inactivation selectively, enhanced $I_{\mathrm{NaP}}$ five-fold and $I_{\mathrm{NaR}}$ three-fold in voltage clamp recordings. In rapidly-adapting SGNs under current clamp, ATX-II increased the likelihood of firing additional action potentials. The data identify $I_{\mathrm{NaP}}$ and $I_{\mathrm{NaR}}$ as novel regulators of excitability in SGNs, and consistent with their roles in other neuronal types, we suggest that these nonclassical $\mathrm{Na}^{+}$currents may contribute to the control of refractoriness in the auditory nerve.
\end{abstract}

Key words: cochlea; hearing; ion channels; persistent current; resurgent current; spiral ganglion

\section{Significance Statement}

Neurons in the auditory nerve are renowned for their ability to fire action potentials at high rates. This is essential for the brain's normal coding of acoustic signals, and in humans this information is important for deciphering speech, and for determining the frequency and loudness of sounds. Here, we describe mechanisms that may contribute to this rapid spiking. Nonclassical $\mathrm{Na}^{+}$currents increase the excitability and decrease the refractoriness of spiral ganglion neurons (SGNs), enabling them to fire spikes at high rates for prolonged periods. Knowing how these currents contribute to normal auditory nerve function may improve our understanding of peripheral auditory neuropathies, and identify novel drug targets for the treatment of conditions causing hearing loss.

\section{Introduction}

The auditory nerve connects the cochlea to the cochlear nucleus, and so acts as the gateway to the hearing

Received August 31, 2017; accepted October 17, 2017; First published November 7, 2017.

The authors declare no competing financial interests.

Author contributions: D.J.J. designed research; L.B. and K.E.S. performed research; L.B., K.E.S., and D.J.J. analyzed data; L.B., K.E.S., and D.J.J. wrote the paper. brain. Individual spiral ganglion neurons (SGNs) convey the requisite information describing the essential properties of incoming sound, and so preserve the timing cues contributing to coding of frequency, localization and loudness within higher centers. SGNs translate neurotransmitter release from mechano-sensory hair cells into action

This work was supported by the Action on Hearing Loss Grant P35021 (to D.J.J.) and the Biotechnology and Biological Sciences Research Council Grant BB/M019322/1 (to D.J.J.). 
potentials, which are propagated along their neurites forming the main body of the auditory nerve. In the functionally mature cochlea, each inner hair cell $(\mathrm{IHC})$ contacts 5-30 unbranched nerve endings of type I SGNs (Rusznák and Szucs, 2009; Meyer and Moser, 2010; Nayagam et al., 2011; Heil and Peterson, 2015).

Auditory nerve recordings from a number of mammalian species have revealed that SGNs can fire spontaneously in the absence of sound, and that they increase their firing rate in response to presented tones, with the initial rate being proportional to the sound intensity (Heil and Peterson, 2015). Recordings from individual SGNs in mice have demonstrated peak discharge rates $>1 \mathrm{kHz}$ (Taberner and Liberman, 2005), which then adapt to steady state levels $>200 \mathrm{~Hz}$, suggesting these neurons employ specialized mechanisms that support repetitive rapid spiking and ensure extremely short refractory periods. Patch clamp recordings and immuno-labeling experiments have suggested that the expression of numerous ion channel subtypes contributes to shaping the firing properties of SGNs, in mice and rats (Jagger and Housley, 2002, 2003; Hossain et al., 2005; Wang et al., 2013; Crozier and Davis, 2014; Smith et al., 2015; Kim and Rutherford, 2016; Wright et al., 2016), and in guinea pigs (Santos-Sacchi, 1993; Szabó et al., 2002). Following hearing onset, increases in firing rates and shortening of the refractory period are observed (Wu et al., 2016). This maturation of firing properties may in part be explained by the recruitment of voltage-gated $\mathrm{Na}^{+}$channels and $\mathrm{K}^{+}$channels to distinct subcellular microdomains (Kim and Rutherford, 2016). The outcome is a microsecond postsynaptic precision in functionally mature SGNs that preserves the timing of presynaptic neurotransmitter release (Rutherford et al., 2012).

Elsewhere in the nervous system, rapid spiking behavior is often associated with mechanisms that avoid long-lasting $\mathrm{Na}^{+}$channel inactivation in preference for alternative states that enable shorter refractory periods. "Persistent" $\mathrm{Na}^{+}$currents $\left(I_{\mathrm{NaP}}\right)$ activate at membrane potentials just below the spike threshold, and can amplify the response to synaptic inputs and enhance the neuronal capability to fire repetitively (Crill, 1996; Stafstrom, 2007). "Resurgent" $\mathrm{Na}^{+}$currents $\left(\mathrm{I}_{\mathrm{NaR}}\right)$ activate transiently during an action potential repolarization following the initial strong depolarization, raising the likelihood of a second spike (Bean, 2007; Theile and Cummins, 2011; Lewis and Raman, 2014). Here we provide the first description of comparable tetrodotoxin (TTX)-sensitive currents in SGNs cultured from mice. Nav1.6 $\alpha$-subunits and regulatory Nav $\beta 4$ subunits are suggested to mediate these currents in other neuronal types (Theile and Cummins, 2011; Lewis and Raman, 2014), and in fixed cochlear sections these

Correspondence should be addressed to Daniel J. Jagger, Ph.D., UCL Ear Institute, University College London, 332 Gray's Inn Road, London WC1X 8EE, United Kingdom, E-mail: d.jagger@ucl.ac.uk.

DOI:http://dx.doi.org/10.1523/ENEURO.0303-17.2017

Copyright (C) 2017 Browne et al.

This is an open-access article distributed under the terms of the Creative Commons Attribution 4.0 International license, which permits unrestricted use, distribution and reproduction in any medium provided that the original work is properly attributed. subunits were both localized within domains that regulate spike generation and propagation in the auditory nerve. The currents emerged at the end of the first postnatal week, and increased their prevalence around the onset of hearing. Pharmacological modulation of $I_{\mathrm{NaP}}$ and $\mathrm{I}_{\mathrm{NaR}}$ altered the excitability and firing behavior of SGNs, suggesting these anti-refractory mechanisms could play key roles in the regulation of spike firing in the mature auditory nerve.

\section{Materials and Methods}

\section{Animals}

C57BL/6 mice of either sex were bred within an inhouse facility, and were killed by cervical dislocation and subsequent decapitation. All animal work conformed to United Kingdom legislation outlined in the Animals (Scientific Procedures) Act 1986.

\section{SGN culture}

The cochleae of mice of either sex between postnatal day 0 (P0) and P90 were removed and the bony modioli isolated. The tissue was digested in $0.25 \%$ trypsin at $37^{\circ} \mathrm{C}$ for 30 min. Growth medium (DMEM containing 10\% FCS, $10 \mathrm{mM}$ HEPES, and 1\% penicillin/streptomycin) was added and the tissue was gently triturated. Cells were pelleted by gentle centrifugation $(400 \times g, 10 \mathrm{~min})$, resuspended in growth medium, and then plated onto glass coverslips pretreated with poly-L-lysine $(50 \mu \mathrm{g} / \mathrm{ml})$. Coverslips were incubated in a humidified incubator at $37^{\circ} \mathrm{C}$, $5 \% \mathrm{CO}_{2}$, for $1 \mathrm{~h}$ to allow the dissociated SGNs to adhere, and then growth medium supplemented with $10 \mathrm{ng} / \mathrm{ml}$ brain-derived neurotrophic factor (BDNF) was added. Patch clamp recordings were performed following 1-2 d in vitro. Chemicals were obtained from Sigma-Aldrich unless stated otherwise.

\section{SGN electrophysiology}

Recordings were conducted in the whole-cell configuration using an Axopatch 200B patch clamp amplifier (Molecular Devices) and a Digidata board (Molecular Devices) under the control of pClamp software (version 8 , Molecular Devices). During initial recordings cultures were superfused with artificial perilymph (containing $145 \mathrm{mM}$ $\mathrm{NaCl}, 4 \mathrm{mM} \mathrm{KCl}, 1 \mathrm{mM} \mathrm{MgCl}$, $1.3 \mathrm{mM} \mathrm{CaCl}_{2}, 10 \mathrm{mM}$ HEPES, and $5 \mathrm{mM}$ glucose; $\mathrm{pH}$ adjusted to 7.3 with $\mathrm{NaOH}$ ) under the control of a peristaltic pump. Patch pipettes were pulled from capillary glass (GC120TF; Harvard Apparatus) using a vertical puller (PP-830; Narishige). Pipettes had resistances of 3-4 $\mathrm{M} \Omega$ when filled with an intracellular solution containing $130 \mathrm{mM}$ K-gluconate, $5 \mathrm{mM} \mathrm{KCl}, 2 \mathrm{mM}$ MgATP, $2 \mathrm{mM} \mathrm{Na} \mathrm{Na}_{2}$ ATP, $0.3 \mathrm{mM} \mathrm{Na}_{3} \mathrm{GTP}, 10 \mathrm{mM} \mathrm{Na} \mathrm{Na}_{2}$ phosphocreatine, $1 \mathrm{mM}$ EGTA, and $10 \mathrm{mM}$ HEPES; $\mathrm{pH}$ adjusted to 7.2 with $\mathrm{KOH}$. In some experiments, macroscopic $\mathrm{Na}^{+}$currents $\left(\mathrm{I}_{\mathrm{Na}}\right)$ were recorded in isolation using an extracellular solution supplemented with blockers of $\mathrm{K}^{+}$currents $\left(\mathrm{I}_{\mathrm{K}}\right), \mathrm{Ca}^{2+}$ currents $\left(\mathrm{I}_{\mathrm{Ca}}\right)$, and hyperpolarizationactivated cation currents $\left(\mathrm{I}_{\mathrm{h}}\right)$, containing $145 \mathrm{mM} \mathrm{NaCl}, 4$ $\mathrm{mM} \mathrm{KCl}, 1 \mathrm{mM} \mathrm{MgCl}$, $1.3 \mathrm{mM} \mathrm{CaCl}_{2}, 0.3 \mathrm{mM} \mathrm{CdCl}_{2}$, 2 $\mathrm{mM} \mathrm{CsCl}, 10 \mathrm{mM}$ HEPES, and $5 \mathrm{mM}$ glucose; $\mathrm{pH}$ adjusted to 7.3 with $\mathrm{NaOH}$. For these recordings the intra- 
cellular solution contained $120 \mathrm{mM}$ CsF, $25 \mathrm{mM}$ TEA-Cl, 2 mM MgATP, 2 mM Na 2 ATP, $0.3 \mathrm{mM} \mathrm{Na}_{3} \mathrm{GTP}, 2.5 \mathrm{mM}$ $\mathrm{Na}_{2}$-phosphocreatine, $1 \mathrm{mM}$ EGTA, and $10 \mathrm{mM}$ HEPES; $\mathrm{pH}$ adjusted to 7.2 with TEA-OH. TTX-sensitive currents were obtained by digital subtraction of averaged $(2 \times)$ recordings in the presence of TTX from averaged recordings in control conditions. The TTX-sensitive current is denoted as "difference current" in the text. Consistent with the existing literature, maximum persistent $\mathrm{Na}^{+}$current $\left(I_{\mathrm{NaP}}\right)$ and resurgent $\mathrm{Na}^{+}$current $\left(\mathrm{I}_{\mathrm{NaR}}\right)$ amplitudes in individual SGNs are expressed as a percentage of the maximum transient $\mathrm{Na}^{+}$current $\left(I_{\mathrm{NaT}}\right)$ measured in the same cell. Liquid junction potentials were calculated and subtracted off-line. Series resistance compensation was applied routinely at $70 \%$. All recordings were performed at room temperature $\left(22-24^{\circ} \mathrm{C}\right)$. Current clamp and voltage clamp protocols are described in the results section and in figure legends. Electrophysiological data were analyzed off-line using Clampfit (version 10; Molecular Devices), Igor Pro (version 6.36, Wavemetrics), and OriginPro 2016 (OriginLab). The voltage dependence of activation and inactivation were calculated by fitting conductance-voltage data with the Boltzmann function, $G_{\text {norm }}=G_{\min }+\left(G_{\max }-G_{\min }\right) /\left(1+\exp \left(\left(V_{1 / 2}-V_{m}\right) / k\right)\right)$, where $G$ is conductance, $V_{1 / 2}$ is the voltage of halfmaximal activation or inactivation, $V_{m}$ is the membrane potential, and $k$ is the slope factor.

\section{Drug stocks and application}

Dendrotoxin-K (DTX-K), TTX, 4,9-anhydro-TTX (4,9-ahTTX), and sea anemone (Anemonia sulcata) toxin ATX-II were all obtained from Alomone Labs. Toxins were prepared as stock solutions in water and stored at $-20^{\circ} \mathrm{C}$, before dilution in extracellular solution for patch clamp recordings.

\section{Antibodies}

The mouse monoclonal neuronal class III $\beta$-tubulin antibody (TUJ1; subtype $\operatorname{lgG}_{2 a}$; Covance, Princeton) was used as a neuronal marker. Nav1.6 subunits were detected using a rabbit polyclonal anti-Nav1.6 antibody (ASC-009; Alomone Labs). Mouse monoclonal antibodies against $N a v \beta 4$ (subtype IgG ; $_{1}$ clone N168/6), Kv1.2 (subtype $\lg _{2 \mathrm{~b}}$; clone $\mathrm{K} 14 / 16$ ) and Caspr (subtype $\operatorname{lgG}_{1}$; clone K65/35) were obtained from the UC Davis/NIH NeuroMab Facility. Mouse monoclonal antibodies were detected by the application of isotype-specific secondary antibodies: Alexa Fluor 488 goat anti-mouse $\operatorname{lgG}_{2 \mathrm{~b}}$, Alexa Fluor 555 goat anti-mouse $\operatorname{lgG}_{1}$ and Alexa Fluor 633 goat antimouse $\lg _{2 a}$ (Life Technologies). Alexa Fluor conjugated goat or donkey anti-rabbit secondary antibodies were used to detect the rabbit anti-Nav1.6 antibody (Life Technologies).

\section{Immunofluorescence}

Whole cochleae from P21 mice were fixed in either $2 \%$ (for Nav $\beta 4$ labeling) or $4 \%$ paraformaldehyde in PBS for $40 \mathrm{~min}$ at room temperature. The fixed cochleae were washed several times in PBS, and then decalcified in 4\% EDTA for $48 \mathrm{~h}$, at $4^{\circ} \mathrm{C}$. The semicircular canals were removed and the remaining otic capsules were mounted in $4 \%$ low-melting point agarose and sectioned on a vibratome (1000 plus system, Intracel) at $150-$ to $200-\mu \mathrm{m}$ intervals. Antibody labeling was performed on midmodiolar sections. Following an initial block and permeabilization (10\% normal goat serum and $0.2 \%$ Triton X-100 in PBS) for $1 \mathrm{~h}$ at room temperature, the sections were further incubated in Mouse Ig Blocking Reagent (Vector Laboratories), for $1 \mathrm{~h}$ at room temperature, to minimize the background fluorescence of the mouse tissue. All primary antibodies were diluted 1:100, with the exception of TUJ1 (1:500), in lysine blocking solution ( $0.1 \mathrm{M}$ lysine and $0.2 \%$ Triton X-100 in PBS). In control experiments the primary antibodies were omitted. For Nav1.6 labeling, primary antibodies were incubated for $3.5 \mathrm{~h}$ at room temperature. For anti-Nav $\beta 4$ experiments, the primary antibodies were incubated overnight at $4^{\circ} \mathrm{C}$. Following several washes in PBS, the sections were incubated in Alexa Fluor secondary antibodies diluted 1:400 in lysine blocking solution at room temperature for $1 \mathrm{~h}$. After a final set of washes in PBS, sections were mounted in Vectashield containing DAPI (Vector Laboratories). Images were acquired using a $20 \times$ air immersion objective (N.A. 0.75 ) or a $63 \times$ water immersion objective (N.A. 1.2) of an LSM510 confocal microscope (Carl Zeiss Microscopy) equipped with 405, 488, 543, and $633 \mathrm{~nm}$ lasers; 505-530 and 560-615 nm bandpass filters were used to collect Alexa Fluor 488 and 555 emissions, respectively. A $650 \mathrm{~nm}$ long-pass filter was used to collect Alexa Fluor 633 emission. DAPI emission was collected using a 420$480 \mathrm{~nm}$ bandpass filter. Multi-channel z-stacks were acquired using sequential scanning, with a frame average of 4 and a $z$-step size of $2.3 \mu \mathrm{m}(20 \times)$ or $1.4 \mu \mathrm{m}(63 \times)$. Images showing Nav channel immunofluorescence are maximum intensity $z$-projections of two adjacent sections (spiral ganglion region), or four adjacent sections (hair cell region).

\section{Experimental design and statistical analysis}

For group data the values given in the text are mean data \pm the standard error of the mean. In experiments with low $n$ values, representative measurements or traces are shown alongside the number of observations made. Where appropriate, normality of datasets was assessed using the Shapiro-Wilk test, and an $F$ test was used to assess if the variances were equal between groups. Where data fulfilled the requirements for parametric analysis, statistical significance was determined using Student's $t$ test. A Mann-Whitney $U$ test or Wilcoxon signedrank test analyzed nonparametric data where appropriate. ANOVA determined differences between three or more means. To test for within and between group effects, analysis was conducted using the standard Bonferroni posthoc test. Alternatively, when it was necessary to run multiple tests in the absence of an ANOVA analysis, multiple $t$ tests or Mann-Whitney $U$ tests were performed manually and Bonferroni correction was used to avoid possible type- 1 errors resulting from multiple comparisons. All $p$ values were reported relative to a significance level $(\alpha)$ of 0.05 . 
A

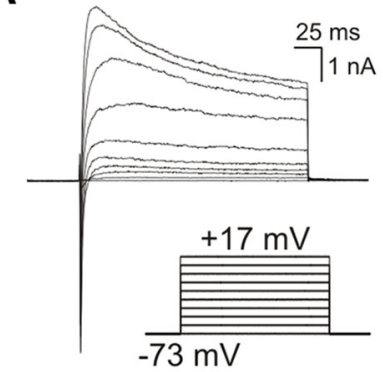

C

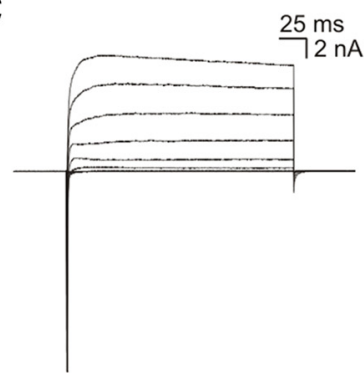

E

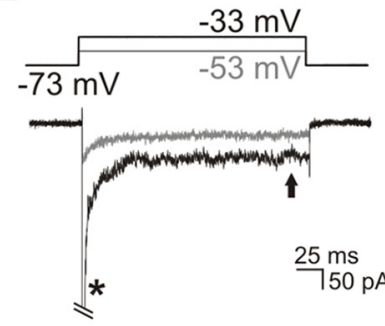

B

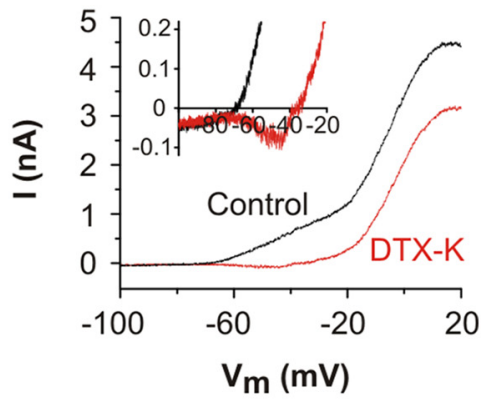

D

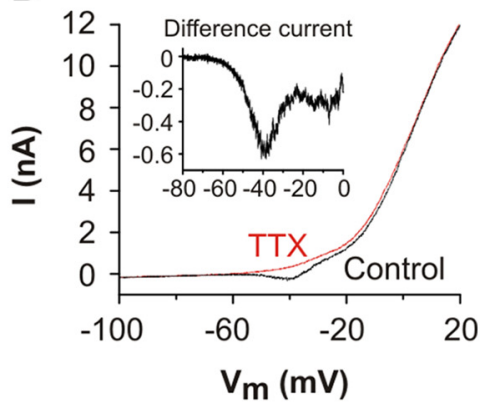

$\mathbf{F}$

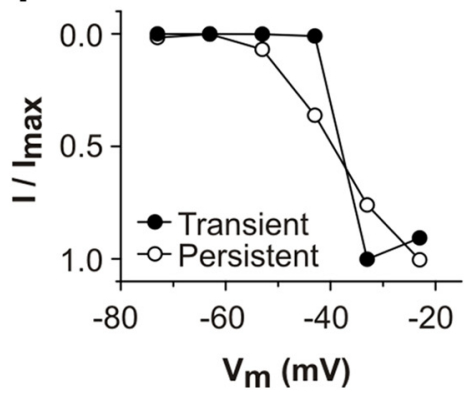

Figure 1. TTX-sensitive transient and persistent $\mathrm{Na}^{+}$currents identified in SGNs cultured from hearing mice. $\boldsymbol{A}$, Current responses recorded using $\mathrm{K}^{+}$-filled patch electrodes, from a representative rapidly-adapting P14 SGN during 200-ms voltage steps. A transient inward $\mathrm{Na}^{+}$current $\left(\mathrm{I}_{\mathrm{NaT}}\right)$ was followed by LVA and HVA outward $\mathrm{K}^{+}$currents. $\boldsymbol{B}$, Current response from the same cell during a voltage ramp (between -143 and $+47 \mathrm{mV}$, duration $400 \mathrm{~ms}$ ) before (control) and after bath application of $100 \mathrm{nM}$ DTX-K. DTX-K blocked the LVA $\mathrm{K}^{+}$current, revealing a small inward current activated at potentials positive to $-65 \mathrm{mV}$ (detailed in the inset). $\boldsymbol{C}$, Current responses recorded using $\mathrm{K}^{+}$-filled patch electrodes, from a representative nonadapting P14 SGN during 200-ms voltage steps (protocol described in $\boldsymbol{A}$ ). Activation of $\mathrm{I}_{\mathrm{NaT}}$ was followed by activation of HVA K ${ }^{+}$currents. LVA K ${ }^{+}$currents were absent from this cell. $\boldsymbol{D}$, Current responses from the same SGN, during a voltage ramp before (control) and after bath application of $100 \mathrm{nM}$ TTX. A TTX-sensitive inward current activated at potentials positive to $-65 \mathrm{mV}$ (difference current, detailed in the inset). $\boldsymbol{E}$, TTX-subtracted currents recorded from the SGN in $\boldsymbol{D}$, during $200-\mathrm{ms}$ depolarizing voltage steps. A voltage step to $-53 \mathrm{mV}$ activated a small persistent inward current $\left(\mathrm{I}_{\mathrm{NaP}}\right)$, whereas the voltage step to $-33 \mathrm{mV}$ activated a large $\mathrm{I}_{\mathrm{NaT}}\left(*\right.$, peak current cropped for clarity) and a small $\mathrm{I}_{\mathrm{NaP}}$. $\boldsymbol{F}$, Comparison of the voltage dependence of TTX-sensitive $I_{\mathrm{NaT}}$ and $\mathrm{I}_{\mathrm{NaP}}$ (measured at the arrow in $\boldsymbol{E}$ ) in this SGN.

\section{Results}

\section{Multiple TTX-sensitive $\mathrm{Na}^{+}$currents in SGNs around hearing onset}

Initial whole-cell voltage clamp recordings were conducted on SGNs cultured from mice after the onset of hearing (P12-P14; Fig. 1), and these revealed families of currents that resembled those in studies using comparable preparations (Santos-Sacchi, 1993; Szabó et al., 2002; Smith et al., 2015). At this developmental stage SGNs can be categorized broadly as rapidly-adapting (firing one to two action potentials in response to sustained current injection), slowly-adapting (three to seven action potentials) or nonadapting (tonic firing). In experiments here using $\mathrm{K}^{+}$-containing pipette solutions, depolarizing voltage steps activated transient inward $\mathrm{Na}^{+}$ currents $\left(\mathrm{I}_{\mathrm{NaT}}\right)$ and sustained outward $\mathrm{K}^{+}$currents. In rapidly-adapting SGNs (Fig. $1 A$ ), the outward $\mathrm{K}^{+}$currents had a distinct low voltage-activated (LVA) component in addition to a high voltage-activated (HVA) component. Voltage ramps (between -143 and $+47 \mathrm{mV}$, duration 400 $\mathrm{ms}$ ) revealed the LVA current activated at potentials positive to $-65 \mathrm{mV}$, and the HVA component activated above $-20 \mathrm{mV}$ (Fig. 1B). Selective block of the LVA current by bath-applied DTX-K revealed an underlying inward cur- 
A

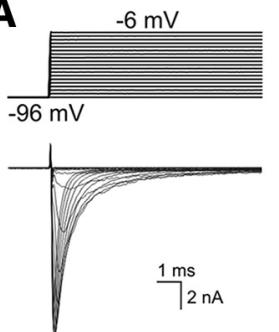

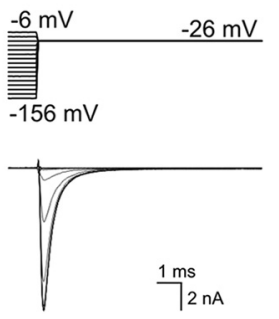

B

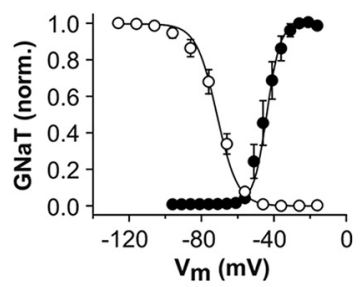

Figure 2. Isolation of transient $\mathrm{Na}^{+}$currents in SGNs cultured from hearing mice. Isolated $\mathrm{Na}^{+}$currents were recorded using $\mathrm{Cs}^{+}$-containing patch electrodes and external medium supplemented with channel blockers (see Materials and Methods). $\boldsymbol{A}$, TTX-sensitive $I_{\mathrm{NaT}}$ recorded in a representative P14 SGN. The voltage clamp protocols shown in the upper panels were used to determine the voltage dependence of activation (left; detail of 20-ms test potentials between -96 and $-6 \mathrm{mV}$, from a holding potential $-96 \mathrm{mV}$ ) and steady-state inactivation (right; detail of 20 -ms test potentials at $-26 \mathrm{mV}$, following 200 -ms conditioning potentials between -156 and $-6 \mathrm{mV}$ ). $\boldsymbol{B}$, Normalized peak conductance-voltage plots showing activation (filled circles) and inactivation (open circles) of the channels underlying TTX-sensitive $I_{\text {NaT }}$ in SGNs cultured from P12-P14 mice $(n=10)$.

rent that activated at potentials positive to $-70 \mathrm{mV}$ and had a maximum amplitude around $-40 \mathrm{mV}$ (Fig. $1 B$, inset).

In nonadapting SGNs there is little measureable LVA current under control conditions (Fig. 1C), and during voltage ramps in such cells there was an inward current that activated around the same voltage range as described above (Fig. 1D). This current was blocked by a low concentration of bath-applied TTX (100 nM). The digitally subtracted TTX-sensitive current had a peak amplitude around $-40 \mathrm{mV}$ (measured as $0.6 \mathrm{nA}$ for the example shown in Fig. 1D, inset). This difference current resembled voltage ramp-activated persistent $\mathrm{Na}^{+}$currents $\left(\mathrm{I}_{\mathrm{NaP}}\right)$, that have been described in a wide variety of neurons (Crill, 1996; Stafstrom, 2007). To further examine this current a voltage step protocol was applied (Fig. 1E). From a holding potential of $-73 \mathrm{mV}$, a depolarizing step to $-53 \mathrm{mV}$ activated $I_{\mathrm{NaP}}$ only, whereas a depolarizing step to -33 $\mathrm{mV}$ activated both $\mathrm{I}_{\mathrm{NaT}}$ and $\mathrm{I}_{\mathrm{NaP}}$. Comparison of the relative activation ranges of these currents confirmed that $I_{\mathrm{NaP}}$ could be elicited at potentials $\sim 20 \mathrm{mV}$ more negative than $\mathrm{I}_{\mathrm{NaT}}$ (Fig. $1 F$ ).

To examine the characteristics of whole-cell Nav currents in isolation, $\mathrm{K}^{+}$currents $\left(\mathrm{I}_{\mathrm{K}}\right)$, hyperpolarizationactivated currents $\left(I_{h}\right)$ and $\mathrm{Ca}^{2+}$ currents $\left(I_{\mathrm{Ca}}\right)$ were minimized (using $\mathrm{Cs}^{+}$-based intracellular pipette solution, and an external solution supplemented with blockers of $I_{K}$, $\mathrm{I}_{\mathrm{h}}$ and $\mathrm{I}_{\mathrm{Ca}}$ - see Materials and Methods). Under these conditions, the voltage dependence of activation and inactivation for the channels underlying the TTX-sensitive $\mathrm{I}_{\mathrm{NaT}}$ were determined in SGNs cultured from hearing mice (P12-P14; Fig. 2A,B). The voltage of half-maximal activation was $-44.21 \pm 2.05 \mathrm{mV}$, with a slope value $(k)$ of $2.86 \pm 0.37 \mathrm{mV}$; the voltage of half-maximal inactivation was $-72.16 \pm 2.03 \mathrm{mV}$ with a slope value of $5.39 \pm 0.25$ $\mathrm{mV}(n=10)$. The activation threshold of $\mathrm{I}_{\mathrm{NaT}}$, around -60 $\mathrm{mV}$, was similar to that described for transient $\mathrm{Na}^{+}$currents in SGNs from adult guinea pigs (Santos-Sacchi, 1993), but the voltage of half-maximal inactivation measured here was slightly hyperpolarized compared to the quoted values of -63 and $-66 \mathrm{mV}$ for guinea pig SGNs.

Following our unexpected observation of $I_{\mathrm{NaP}}$, we next explored the possibility of an additional nonclassical $\mathrm{Na}^{+}$ current in SGNs, namely the resurgent $\mathrm{Na}^{+}$current $\left(\mathrm{I}_{\mathrm{NaR}}\right)$. $\mathrm{I}_{\mathrm{NaR}}$ is prevalent in certain fast-spiking neurons in the CNS, and is suggested to be mediated by an intracellular blocking peptide that plugs the pore of the $\mathrm{Na}^{+}$channel $\alpha$-subunit (Bean, 2007; Lewis and Raman, 2014). Recovery from this alternative mode of inactivation is faster than recovery from classical inactivation, allowing $I_{\mathrm{NaR}}$ to flow during the repolarization phase of an action potential. The combination of this depolarizing current and the pool of available channels provided by rapid relief from inactivation promotes firing of a second spike (Bean, 2007). To activate both $I_{\mathrm{NaP}}$ and $I_{\mathrm{NaR}}$ we employed a voltage clamp protocol used previously to characterize these currents in cerebellar Purkinje neurons (Raman and Bean, 1997). P12-P14 SGNs were subjected to a strong initial depolarization (to $+14 \mathrm{mV}$ ) to fully activate and inactivate $I_{\mathrm{NaT}}$, and were then repolarized to a range of test potentials between -86 and $-16 \mathrm{mV}$ (Fig. $3 A$ ). Repolarization elicited a transient inward $\mathrm{I}_{\mathrm{NaR}}$ at all test potentials, with a maximum amplitude at $-46 \mathrm{mV}$. By maintaining the repolarizing test potential for $>100 \mathrm{~ms}$ we could also characterize the voltage dependence of the channels underlying noninactivating $I_{\mathrm{NaP}}($ Fig. $3 A, C)$. Maximum $\mathrm{I}_{\mathrm{NaR}}$ was $4.61 \pm 0.44 \%$ (range $1.25-12.07 \% ; n=30$ ) of maximum $I_{\mathrm{NaT}}$. In comparison, maximum $\mathrm{I}_{\mathrm{NaP}}$ was only $0.89 \pm$ $0.14 \%$ (range $0.30-3.39 \% ; n=30$ ) of maximum $I_{\mathrm{NaT}}$ (Fig. $3 B$ ). The conductance-voltage plot for the channels underlying $I_{\mathrm{NaP}}$ demonstrated a more hyperpolarized activation $\left(\mathrm{V}_{1 / 2}=-55.84 \pm 2.29 \mathrm{mV}, k=12.71 \pm 2.06 \mathrm{mV} ; n=\right.$ 23; Fig. $3 C$ ) in comparison to $I_{\mathrm{NaT}}$ (Fig. 2B). During each repolarizing step $I_{\mathrm{NaR}}$ activated rapidly but deactivated more slowly (Fig. $3 A, D$ ). During the most hyperpolarized test potentials, the time to peak of $I_{\mathrm{NaR}}$ was measured below $1 \mathrm{~ms}$, and the decay time constant was around 2 $\mathrm{ms}$. During more depolarized test potentials both the rise time and decay were slower (Fig. $3 E$ ), suggesting that the inactivation peptide is expelled from the $\mathrm{Na}^{+}$channel $\alpha$-subunit more rapidly at negative repolarization potentials (Lewis and Raman, 2014).

The expression of Nav1.6 $\alpha$-subunits has been associated with rapid spontaneous and evoked spiking behavior in a number of neuronal subtypes. Some of its functional characteristics facilitate such behavior, including a rela- 
A
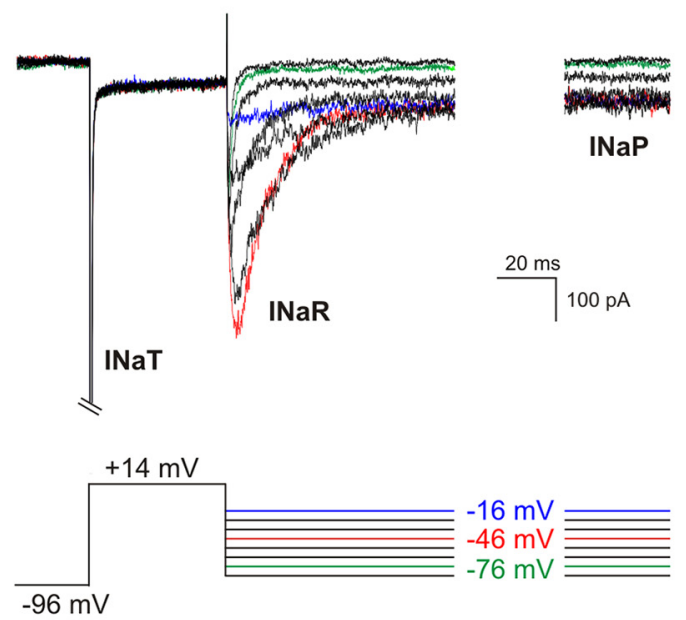

B

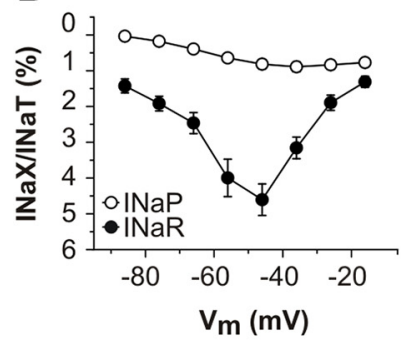

C

D

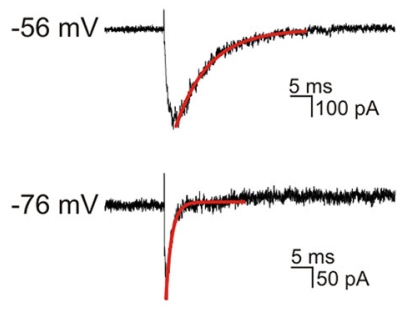

$\mathbf{F}$

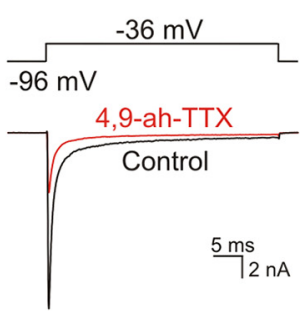

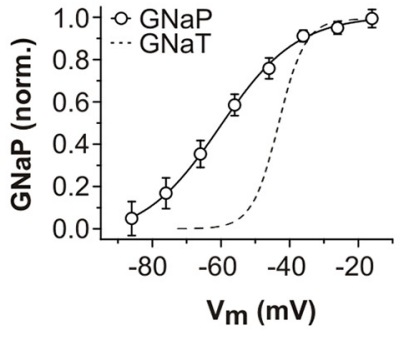

E

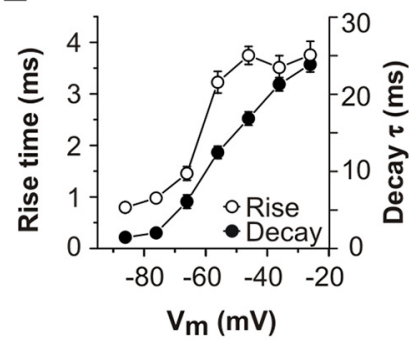

G

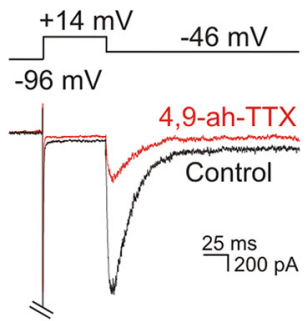

Figure 3. Kinetics, voltage dependence, and pharmacology of resurgent and persistent $\mathrm{Na}^{+}$currents in SGNs. A, Family of TTX-sensitive difference currents evoked by 50 -ms step depolarization to $+14 \mathrm{mV}$, followed by 200 -ms step repolarization to potentials between -16 and $-86 \mathrm{mV}$. Steps to particular potentials are denoted by the colored traces in the voltage protocol. $\mathrm{I}_{\mathrm{NaT}}$ was activated during the steps to $+14 \mathrm{mV}$ (cropped for clarity). I $\mathrm{NaR}_{\mathrm{Na}}$ activated rapidly on repolarization and then decayed, revealing the noninactivating $I_{\mathrm{NaP}}$ at the end of the test steps. $\boldsymbol{B}$, Current-voltage $(I-V)$ relationships for maximum TTXsensitive $I_{\mathrm{NaR}}$ (filled circles) and steady-state $\mathrm{I}_{\mathrm{NaP}}$ (open circles; measured between 160 and $190 \mathrm{~ms}$ after the onset of the repolarization steps). $\mathrm{I}_{\mathrm{NaR}}$ and $\mathrm{I}_{\mathrm{NaP}}$ are shown as a percentage of maximum $I_{\mathrm{NaT}}$ recorded in the same cell $(n=30$; P12-P14). $\boldsymbol{C}$,

Figure 3. continued

Normalized steady-state conductance-voltage plot for the channels underlying $I_{\mathrm{NaP}}$ (open circles), fitted with a Boltzmann function ( $n=23$; P12-P14). For comparison, the peak conductancevoltage plot for $I_{\mathrm{NaT}}$ is also shown (discontinuous line, from Fig. $2 B)$. $\boldsymbol{D}$, The kinetics of activation and decay of $\mathrm{I}_{\mathrm{NaR}}$ varied with repolarization potential. During the protocol used in $\boldsymbol{A}$, repolarization to $-76 \mathrm{mV}$ elicited a current with shorter rise time and decay (exponential fit overlaid in red) compared to that elicited by repolarization to $-56 \mathrm{mV}$. $\boldsymbol{E}$, Mean onset (time to peak) and offset (decay time constant) kinetics of $\mathrm{I}_{\mathrm{NaR}}$ in 19 SGNs (P12P14). $\boldsymbol{F}, \boldsymbol{G}, 4,9-$ ah-TTX, a toxin specific for Nav1.6 subunits blocks $I_{\mathrm{NaT}}$, $I_{\mathrm{NaR}}$ and $I_{\mathrm{NaP}} . \boldsymbol{F}$, A depolarizing voltage step to -36 $\mathrm{mV}$ activated $\mathrm{I}_{\mathrm{NaT}}$ (black trace), which was blocked $>70 \%$ by bath applied $100 \mathrm{nM}$ 4,9-ah-TTX (red). G, A repolarization from +14 to $-46 \mathrm{mV}$ activated $\mathrm{I}_{\mathrm{NaR}}$ and $\mathrm{I}_{\mathrm{NaP}}$ (black trace), which were both blocked $\sim 70 \%$ by bath applied $100 \mathrm{nM}$ 4,9-ah-TTX (red).

tively hyperpolarized voltage dependence of activation, a resistance to inactivation during trains of action potentials, an expression at high densities at sites of action potential generation, and its prominent involvement in the generation of $\mathrm{I}_{\mathrm{NaP}}$ and $\mathrm{I}_{\mathrm{NaR}}$ (O'Brien and Meisler, 2013). Nav1.6 subunit expression has been reported previously in SGNs of mice (Hossain et al., 2005) and rats (Fryatt et al., 2009; Kim and Rutherford, 2016). To investigate the possible contribution of Nav1.6 subunits to the Nav currents in cultured mouse SGNs, we used the TTX metabolite 4,9-ah-TTX, which at $100 \mathrm{nM}$ is a specific blocker of these channels (Rosker et al., 2007). The application of $100 \mathrm{nM} 4,9$-ah-TTX reduced the amplitude of $\mathrm{I}_{\mathrm{NaT}}$ activated during depolarizing test potentials by $71.7 \pm 3.4 \%$ $\left(n=6\right.$; Fig. $3 F$ ), and reduced the amplitude of $\mathrm{I}_{\mathrm{NaR}}$ and $\mathrm{I}_{\mathrm{NaP}}$ activated during a repolarizing step to $-46 \mathrm{mV}$ by $67.4 \pm$ 4.2 and $70 \pm 3.3 \%$, respectively ( $n=6$; Fig. $3 G$ ). The relative (\%) reduction in amplitude of the three currents was not significantly different (ANOVA, $F_{(2,15)}=0.34, p=$ $0.71)$. These observations suggest that Nav1.6 subunits most likely contribute to all three $\mathrm{Na}^{+}$currents in SGNs, and that one population of channels operates in a multimodal fashion to mediate separate currents under specific circumstances. The residual currents in the presence of 4,9-ah-TTX may represent unblocked Nav1.6 channels (requiring a higher, although less selective, dose of 4,9ah-TTX), or they may be mediated by subunits not targeted by the toxin. Further functional studies are required to characterize the specific molecular basis of these currents.

\section{Nav $\beta 4$ subunits localize to the spike initiator and perisomatic nodes of Ranvier}

Nav1.6 $\alpha$-subunits are most likely modulated by $\mathrm{Nav} \beta 4$ accessory subunits to mediate $\mathrm{I}_{\mathrm{NaR}}$ in cerebellar Purkinje neurons (Grieco et al., 2005), although other proteins may contribute to the process (Yan et al., 2014; Ransdell et al., 2017). The cytoplasmic tail of the Nav $\beta 4$ subunit is proposed to enact an open channel block during strong depolarizations, preventing conventional fast inactivation of Nav1.6 subunits, and this blocking peptide then dissociates readily from the $\alpha$-subunit when the cell is repolarized to enable an inward resurge of current (Theile and 

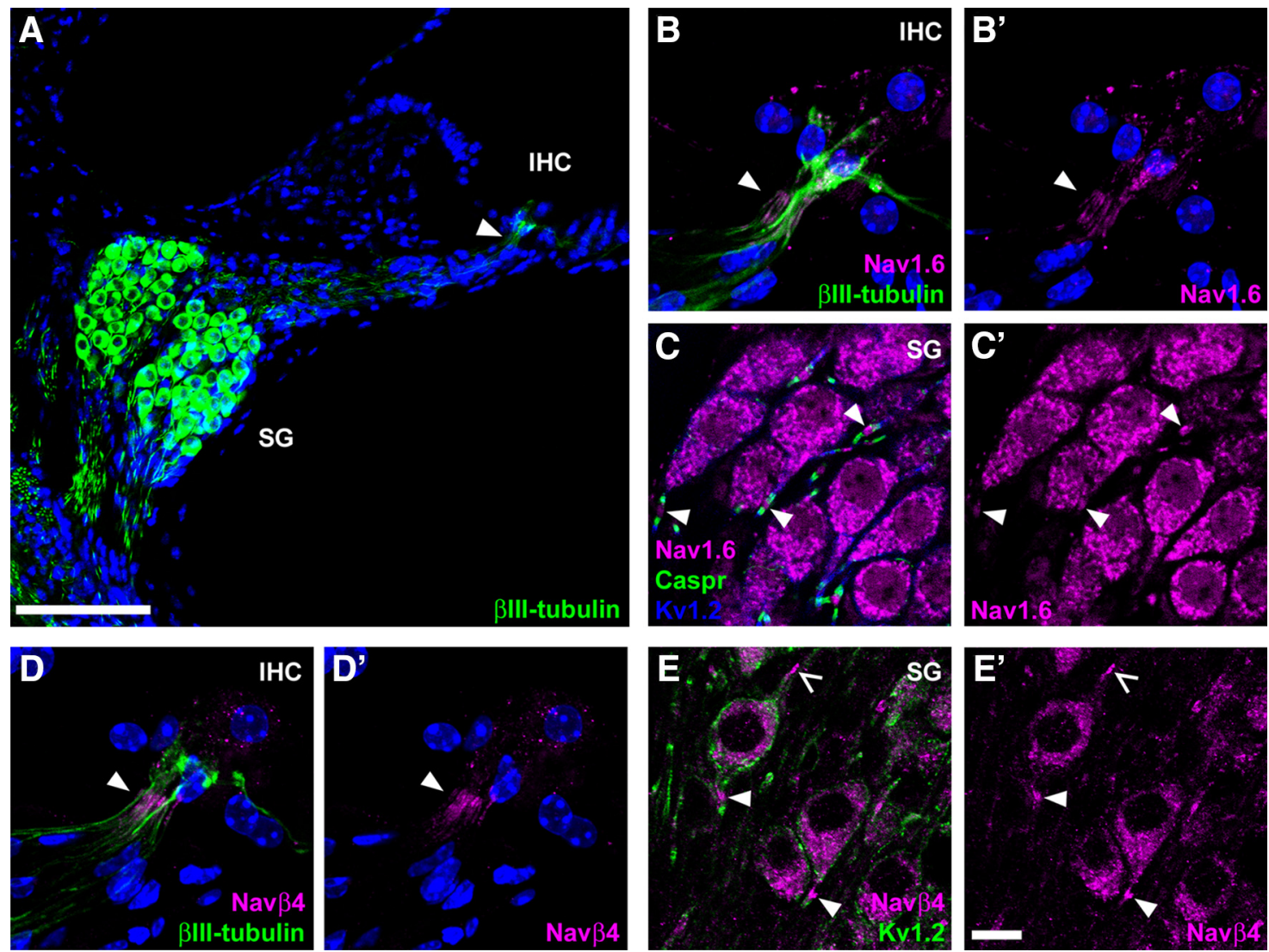

Figure 4. Nav $\beta 4$ subunits localize to neuronal microdomains associated with spike generation and propagation. $\boldsymbol{A}$, SGN cell bodies reside in the spiral ganglion (SG), with their peripheral neurites extending toward an IHC. Arrowhead indicates the first heminode region, the site of action potential initiation. Nuclei were labeled using DAPI (blue). Scale bar, $100 \mu \mathrm{m}$. B- $\boldsymbol{B}^{\prime}$, Immunofluorescence for Nav1.6 subunits localizes to the first heminode (arrowhead) below the IHC. Nuclei were labeled using DAPI (blue). C-C', Within the SG, Nav1.6 subunits localize to pre- and postsomatic nodes of Ranvier (arrowheads), in addition to strong cytoplasmic expression within the soma of SGNs. Caspr and Kv1.2 antibodies label paranodal and juxtaparanodal regions, respectively. D-D', Immunofluorescence for Nav $\beta 4$ subunits localizes to the first heminode (arrowhead). Nuclei were labeled using DAPI (blue). E-E', Within the SG, $\mathrm{Nav} \beta 4$ subunits localize to pre-somatic (open arrow) and post-somatic (arrowheads) nodes of Ranvier. Scale bar in $\boldsymbol{E}^{\prime}, 10 \mu \mathrm{m}$, refers to panels $\boldsymbol{B}-\boldsymbol{E}$.

Cummins, 2011; Lewis and Raman, 2014). The mechanism of $I_{\mathrm{NaP}}$ generation is presently less clear, although it may result from incomplete classical inactivation of $\mathrm{Nav}$ subunits (Crill, 1996). Following the electrophysiological identification of $I_{\mathrm{NaR}}$ in SGNs and its blockade by a Nav1.6-specific toxin, we next sought to determine if Nav $\beta 4$ subunits were expressed in the neuronal microdomains associated with action potential generation and propagation within the auditory nerve. For these experiments we used a mouse monoclonal antibody which has been characterized previously (Buffington and Rasband, 2013), and which has been found to be specific for the Nav $\beta 4$ subunit.

$\beta$ Ill-tubulin immunofluorescence demonstrated the bipolar morphology of SGNs within vibratome sections cut from the cochleae of young adult mice (Fig. 4A). Their somata reside in the spiral ganglion with their peripheral neurites extending to the sensory $\mathrm{IHCs}$, and their central neurites extending toward the brainstem. Action potentials are generated in the peripheral neurites close to the synapses with IHCs, where Nav and Kv channel subunits are arranged within a heminodal structure (Hossain et al.,
2005; Smith et al., 2015; Kim and Rutherford, 2016). Action potentials are propagated along the peripheral neurites via nodes of Ranvier, with pre-somatic and postsomatic nodes of Ranvier either side of the SGN somata. Nav1.6 subunits have been localized previously to the first heminode and nodes of Ranvier in SGNs of mice and rats, and they are proposed to be key contributors to action potential initiation and propagation (Hossain et al., 2005; Kim and Rutherford, 2016). Consistent with these findings, in cochlear sections from P21 mice Nav1.6 immunofluorescence was localized to the first heminode (Fig. $4 B$, arrowhead) and to nodes of Ranvier, including the peri-somatic nodes in the spiral ganglion (Fig. 4C, arrowheads). Here, Nav1.6 immunofluorescence was flanked by labeling for the paranodal marker Caspr (Kim and Rutherford, 2016), and by labeling for the juxtaparanodal marker Kv1.2 (Smith et al., 2015). Nav $\beta 4$ immunofluorescence also localized to the first heminode (Fig. 4D, arrowhead) and to nodes within the spiral ganglion (Fig. $4 E$, arrowheads). There was no labeling of these structures in the control experiments where the primary antibodies were omitted (data not shown). The localization of Nav1.6 
A
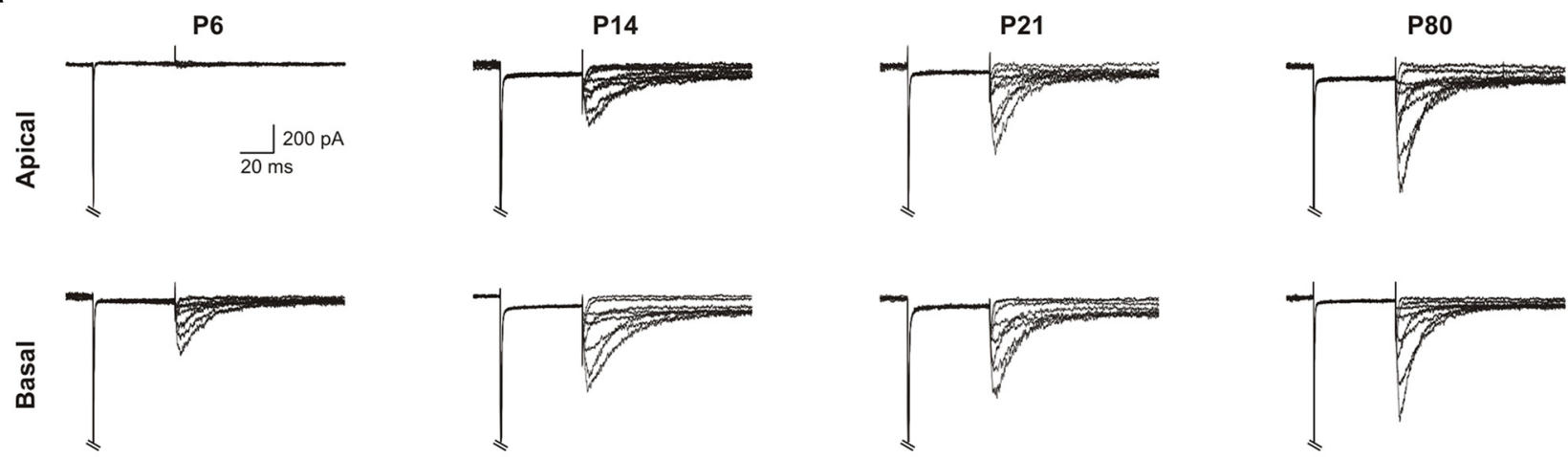

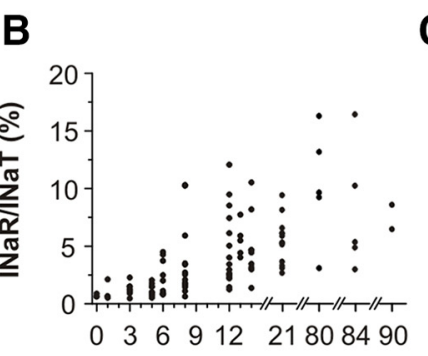

Age (days)
C

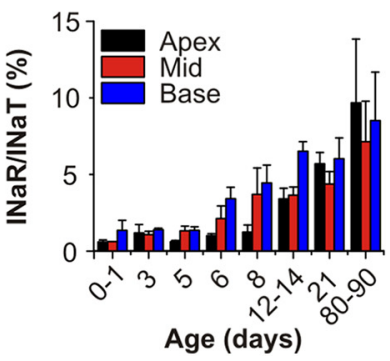

D

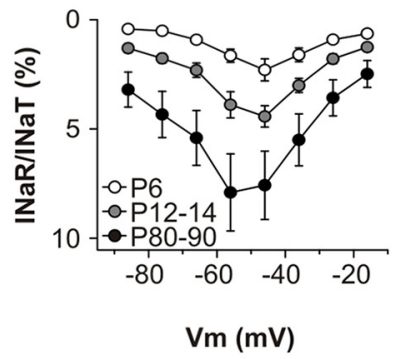

E

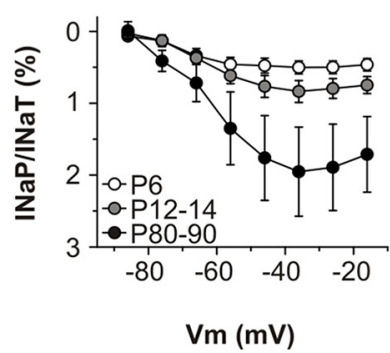

Figure 5. Persistent and resurgent $\mathrm{Na}^{+}$currents have an increased prevalence by hearing onset. $\boldsymbol{A}$, Representative $\mathrm{Na}^{+}$currents elicited in basal and apical SGNs, at developmental stages before (P6) and after the onset of hearing (P14, P21, P80). TTX-sensitive difference currents were elicited using the voltage protocol in Figure $3 A$. B, Scatter plot of $I_{N a R} / I_{N a T}$ ratios for individual SGNs at various developmental ages. $\boldsymbol{C}$, Variations in $\mathrm{I}_{\mathrm{NaR}} / \mathrm{I}_{\mathrm{NaT}}$ at different tonotopic locations. Individual data from $\boldsymbol{B}$ has been grouped (P0-P1, P3, P5, P6, P8, P12-P14, P21, and P80-P90) and separated into tonotopic origin (base, mid, and apex). D, Mean I $\mathrm{NaR}_{\mathrm{R}} / \mathrm{I}_{\mathrm{NaT}}$ ratio for all SGNs (basal and apical cells pooled) plotted as a function of test potentials at various developmental ages (P6, $n=9 ; \mathrm{P} 12-\mathrm{P} 14$, $n=30$; P80-P90, $n=12$ ). $\boldsymbol{E}$, Mean $\mathrm{I}_{\mathrm{NaP}} / \mathrm{I}_{\mathrm{NaT}}$ ratio plotted as a function of test potentials, for the same cells as in $\boldsymbol{D}$.

and Nav $\beta 4$ immunofluorescence to the same microdomains within SGNs raises the possibility that they interact functionally to mediate $I_{\mathrm{NaR}}$.

\section{Increased prevalence of persistent and resurgent $\mathrm{Na}^{+}$currents by hearing onset}

We extended our investigation of $I_{\mathrm{NaP}}$ and $I_{\mathrm{NaR}}$ to study their first appearance and their subsequent progression during the postnatal period. During this period there is a maturation of spike train properties toward more random firing, and there is a shortening of refractoriness (Wu et al., 2016). In a recent report of neuronal properties in cultured spiral ganglion explants, mature firing behavior was first observed in SGNs derived from the basal (high-frequency coding) region of the cochlea, and subsequently in those from the apical (low-frequency coding) region (Crozier and Davis, 2014). These changes are consistent with the hypothesis that maturation of cellular function in the auditory periphery follows a progression from the base of the cochlea to the apex (Mann and Kelley, 2011).

We examined the relative amplitudes of $I_{\mathrm{NaP}}$ and $I_{\mathrm{NaR}}$ in the different frequency coding regions of the cochlea during the period from birth up to three months of age (Fig. 5). Spiral ganglia were dissected and divided into basal, mid and apical lengths. Dissociated SGNs from these regions were cultured separately, and whole-cell recordings allowed comparison of the relative contribu- tions of $I_{\mathrm{NaT}}, I_{\mathrm{NaP}}$ and $I_{\mathrm{NaR}}$ to the membrane physiology (Fig. 5A). I $\mathrm{NaR}_{\mathrm{Na}}$ was detectable in basal SGNs at the end of the first postnatal week (P6-P8), but not in apical cells (Fig. 5A-C). Soon after hearing onset (P12-P14), $\mathrm{I}_{\mathrm{NaR}}$ was detectable in SGNs from both regions but the relative magnitude of $I_{\mathrm{NaR}}$ was higher in basal SGNs compared to apical SGNs (6.94 \pm 0.82 vs $3.55 \pm 0.82 \% ; n=11$ for each region). This region-specific difference was no longer apparent in SGNs from three-week-old and threemonth-old mice (Fig. 5C). Comparison of the currentvoltage (I-V) relationships for $I_{\mathrm{NaR}}$ (Fig. $5 D$ ) and $I_{\mathrm{NaP}}$ (Fig. $5 E$ ) during this period of development confirmed that these currents increased in amplitude relative to maximum $I_{\mathrm{NaT}}$ at each age. In the most mature age group (P80-P90), the mean $I_{\mathrm{NaR}}$ was $\sim 8 \%$ of maximum $\mathrm{I}_{\mathrm{NaT}}$ (SGNs from basal and apical regions pooled), and in individual SGNs this was measured as high as $17 \%$.

\section{ATX-II maximizes persistent and resurgent $\mathrm{Na}^{+}$ current amplitudes in cultured SGNs}

The sea anemone toxin ATX-II interacts with the gating of Nav channels, resulting in the modulation of nonclassical $\mathrm{Na}^{+}$currents. ATX-II slows conventional inactivation, and in doing so has been observed to enhance $\mathrm{I}_{\mathrm{NaP}}$ and/or $\mathrm{I}_{\mathrm{NaR}}$ in sensorimotor neocortical neurons (Mantegazza et al., 1998), hippocampal neurons (Brand et al., 2000), and dorsal root ganglion neurons (Klinger et al., 2012). In 
A

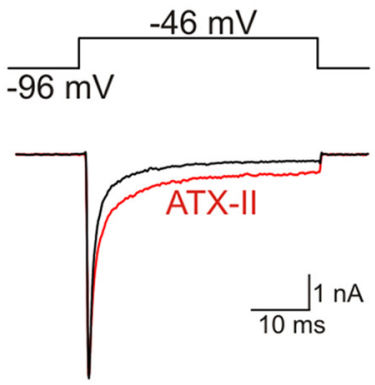

C

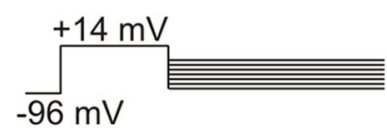

Control
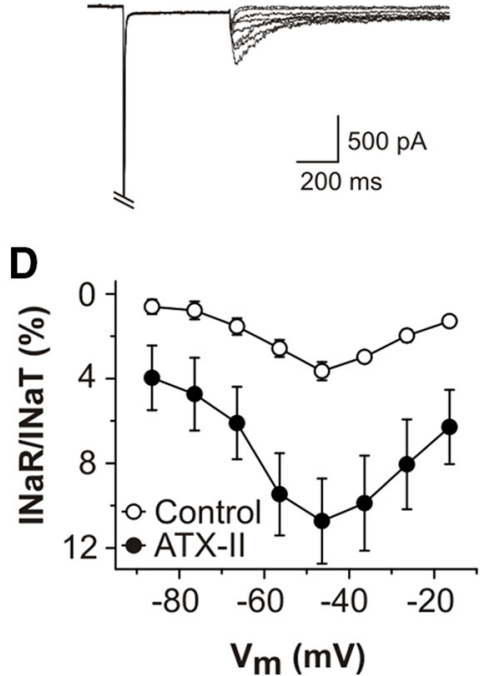

B
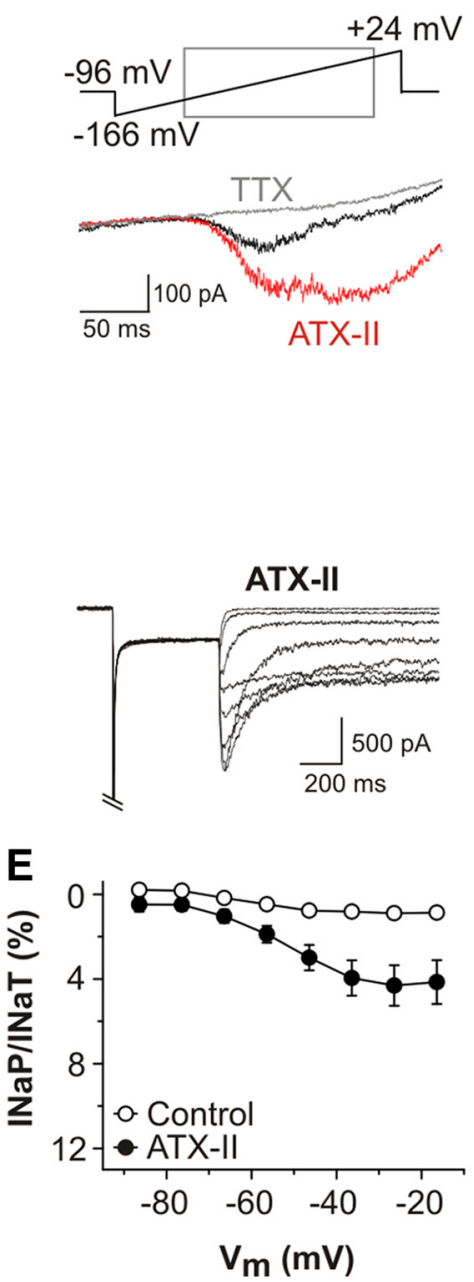

Figure 6. Persistent and resurgent $\mathrm{Na}^{+}$currents are augmented by ATX-II. $\boldsymbol{A}$, TTX-sensitive current responses evoked by depolarizing voltage step protocol (shown above) in a representative P14 SGN, before (black trace) and after bath application of 5 nM ATX-II (red trace). ATX-II slowed the decay kinetics of $I_{\mathrm{NaT}}$. $\boldsymbol{B}, \mathrm{I}_{\mathrm{NaP}}$ elicited during a voltage ramp protocol in the absence of TTX (black trace) and

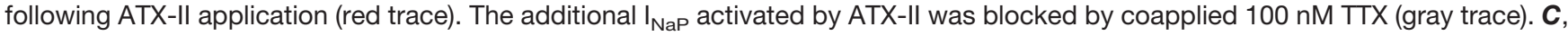
TTX-sensitive difference currents in a P14 SGN in response to voltage clamp protocol shown above, before (control, left) and after $5 \mathrm{nM}$ ATX-II (right). I $\mathrm{NaT}_{\mathrm{T}}$ cropped for clarity. $\boldsymbol{D}$, Mean $\mathrm{I}_{\mathrm{NaR}} / \mathrm{I}_{\mathrm{NaT}}$ ratio plotted as a function of test potential for five P12-P14 SGNs before (open circles) and after $5 \mathrm{nM}$ ATX-II (filled circles). $\boldsymbol{E}$, Mean $\mathrm{I}_{\mathrm{NaP}} / \mathrm{I}_{\mathrm{NaT}}$ ratio plotted as a function of test potentials, before (open circles) and after $5 \mathrm{nM}$ ATX-II (filled circles) for the same SGNs as in $\boldsymbol{D}$.

the case of $\mathrm{I}_{\mathrm{NaR}}$, slowing conventional inactivation is suggested to enable the $\mathrm{C}$ terminus of $\mathrm{Nav} \beta 4$ to achieve open channel block of the $\alpha$-subunit during a strong depolarization. To compare the effects of this toxin on primary auditory neurons, we next examined whether ATX-II could enhance $I_{\mathrm{NaP}}$ and $I_{\mathrm{NaR}}$ in cultured SGNs held under voltage clamp, and then assessed how enhancement of the currents would affect the responses of SGNs under current clamp.

In voltage-clamped P12-P14 SGNs (using $\mathrm{Na}^{+}$current isolation conditions) bath application of $5 \mathrm{nM}$ ATX-II did not affect the maximum amplitude of $\mathrm{I}_{\mathrm{NaT}}$ during $50 \mathrm{~ms}$ depolarizing steps from -96 to $-46 \mathrm{mV}$ but there was a slowing of its inactivation (Fig. 6A). The apparent magnitude of $I_{\mathrm{NaP}}$ increased, an effect which was evident at the end of the depolarizing step in the presence of ATX-II. The enhancement of $I_{\mathrm{NaP}}$ could also be demonstrated using a voltage ramp paradigm (Fig. 6B), and this additional current was blocked by coapplied TTX. During the repolarizing pulse protocol, ATX-II enhanced the $\mathrm{I}_{\mathrm{NaR}} / \mathrm{I}_{\mathrm{NaT}}$ ratio by approximately three-fold (at $-46 \mathrm{mV}$, control $=3.65 \pm$ $0.43 \%$, ATX-II $=10.73 \pm 2.01 \%, n=5$; Fig. 6C,D), and the $\mathrm{I}_{\mathrm{NaP}} / \mathrm{I}_{\mathrm{NaT}}$ ratio by approximately five-fold (at $-26 \mathrm{mV}$, control $=0.89 \pm 0.15 \%$, ATX-II $=4.31 \pm 0.95 \%, n=5$; Fig. 6C,E).

We next sought to simulate the membrane currents flowing through $\mathrm{Na}^{+}$channels during action potentials in the cultured SGNs, to predict how they might contribute to rapid firing behavior in the auditory nerve. To do this we employed the "action potential clamp" technique which was used originally to record $\mathrm{I}_{\mathrm{NaR}}$ in cerebellar Purkinje neurons (Raman and Bean, 1997). For the experiments in Figure 7, a "conglomerate" action potential response was recorded previously in a P21 SGN under current clamp 

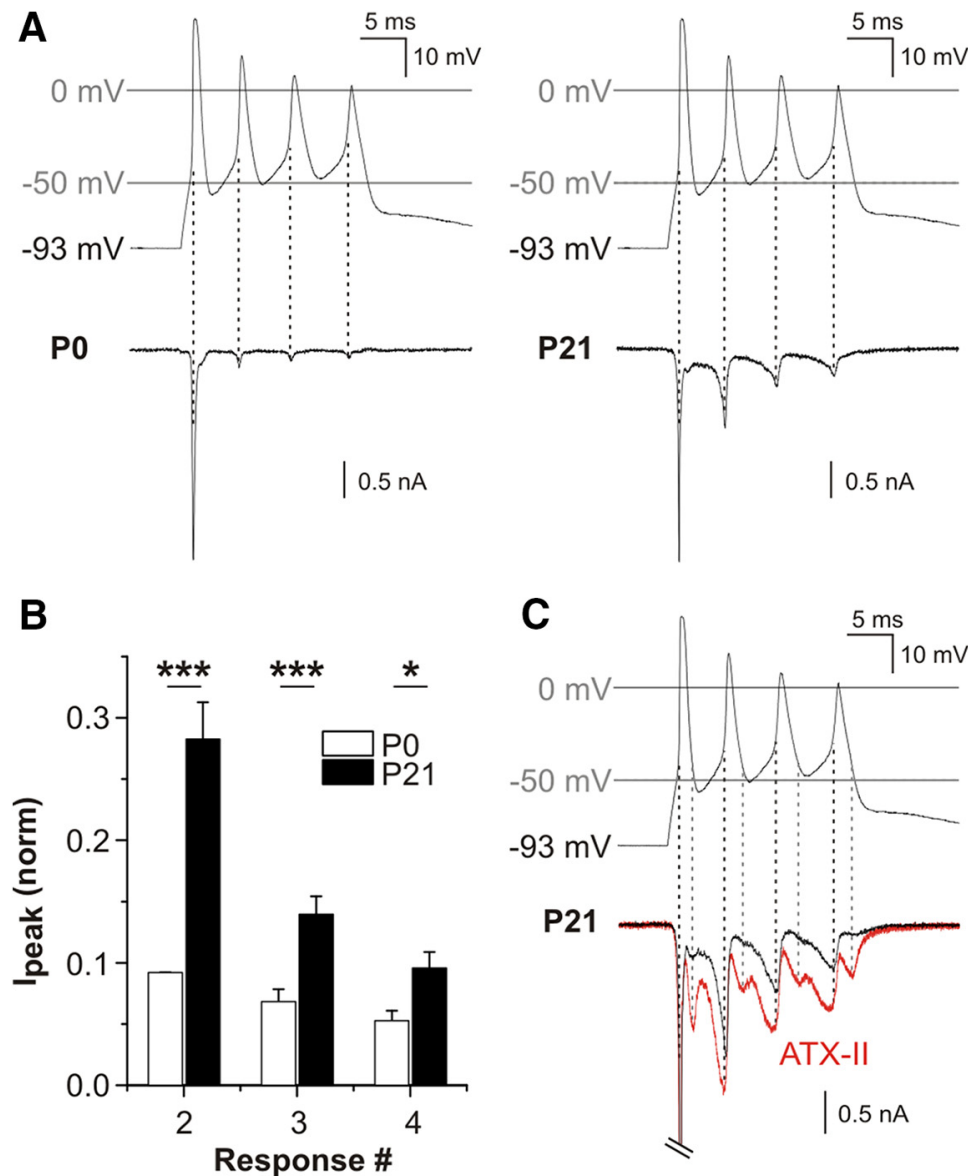

Figure 7. $\mathrm{Na}^{+}$currents elicited by action potential clamp waveforms. $\boldsymbol{A}, \mathrm{Na}^{+}$current responses from a representative P0 SGN (left panel) and a representative P21 SGN (right panel), using a conglomerate action potential as the voltage command stimulus (displayed in upper panels). The action potential wave form was recorded previously from a P21 SGN under current clamp. Isolated $\mathrm{Na}^{+}$currents were recorded using $\mathrm{Cs}^{+}$-filled patch electrodes and an external medium supplemented with channel blockers (see Materials and Methods). In response to the depolarizing phase of the first spike in the wave form, the P0 and P21 SGNs responded with transient inward currents of comparable amplitude. In comparison to the P0 SGN, the P21 SGN was able to generate larger amplitude currents in response to the depolarizing phase of the subsequent three spikes. The peak of the inward currents corresponded to the depolarization phase of the individual spikes within the conglomerate wave form (as denoted by discontinuous black line). $\boldsymbol{B}$, Mean peak currents in response to each spike of the conglomerate action potential, normalized to the first response $(* p<0.05, * * * p<$ $0.001 ; n=5)$. C , Current responses in a P21 SGN elicited by the conglomerate action potential wave form, before (black trace) and after 5 nM ATX-II application (red trace). The response to the first spike (cropped for clarity of subsequent responses) was unchanged after ATX-II. Subsequent responses to the depolarizing phases of command spikes were larger following ATX-II application (denoted by discontinuous black line). After ATX-II, there were augmented inward current responses elicited during the repolarization phase of each spike within the conglomerate wave form (denoted by discontinuous gray line).

mode, and this was used subsequently as the command wave form to be applied to voltage clamped cells. This technique allows ion channels to experience the same trajectory of voltage as during a naturally occurring action potential, and thus any isolated TTX-sensitive $\mathrm{Na}^{+}$current flows with a similar time course and size as during spiking behavior (Bean, 2007).

In PO SGNs (i.e., before $I_{\mathrm{NaR}}$ is observed; Fig. $5 B$ ), the action potential clamp elicited a rapidly-inactivating inward current that coincided with the depolarizing phase of the first spike (Fig. 7A). The depolarization phases of subsequent spikes coincided with relatively smaller evoked inward currents (i.e., responses 2-4). The same procedure applied to P21 SGNs elicited a first inactivating inward current that was comparable in amplitude to that in PO SGNs. However, the currents evoked by the depolarizing phase of the subsequent spikes were all larger in comparison to those in PO cells (Fig. 7B; ANOVA, $F_{(1,24)}=123.36, p=6.09 \times 10^{-11}$ ). The effect of age was significant across all the individual responses (post hoc Bonferroni tests: response 2: $27.7 \pm$ 2.3 vs $8.1 \pm 0.7 \%, p=1.33 \times 10^{-9}$; response $3: 14.1 \pm 1.1$ vs $5.1 \pm 0.8 \%, p=0.0006$; response $4: 9.7 \pm 1.0$ vs $3.7 \pm$ $0.7, p=0.043 ; n=5)$. Throughout the action potential clamp wave form there was a small maintained inward current component in P21 SGNs, which most likely reflected $\mathrm{I}_{\mathrm{NaP}}$ activation. In all cases at P0, however, there was no inward current evident between the evoked responses. This observation suggested that there was no $I_{\mathrm{NaP}}$ at this age, perhaps consistent with the lack of $I_{\mathrm{NaR}}$ in SGNs at this developmental stage (Fig. 5B). 
A
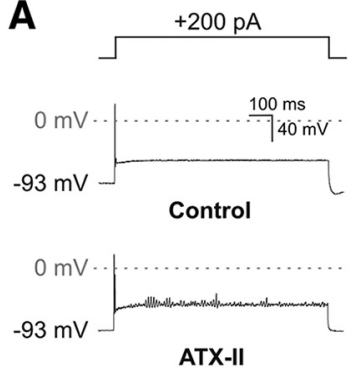

B
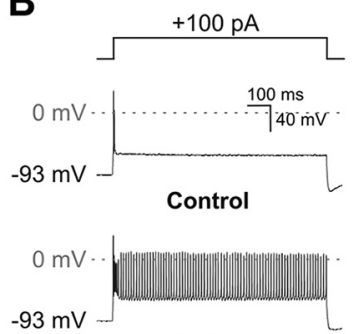

ATX-II

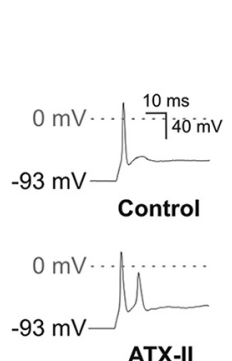

ATX-II
C

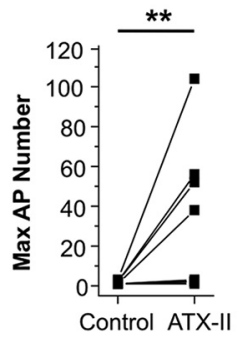

D
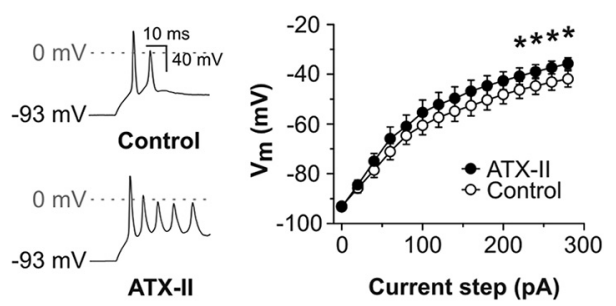

Figure 8. ATX-II application enhanced the excitability of posthearing onset SGNs during current clamp recordings. A, Voltage response from a rapidly-adapting P14 SGN during a sustained depolarizing current injection (shown in upper panel), before (control, middle panel), and after (lower panel) $5 \mathrm{nM}$ ATX-II application. ATX-II application resulted in a slowing of adaptation (inset, right) and oscillation of the membrane potential, typically around $-40 \mathrm{mV}$. B, In another P14 SGN, ATX-II application resulted in a loss of adaptation during sustained depolarizing current injection. $\boldsymbol{C}$, Effect of $5 \mathrm{nM}$ ATX-II on the maximum action potential (AP) number during $800-\mathrm{ms}$ depolarizing current injections in nine rapidly-adapting SGNs $(* * p<0.01 ; n=9)$. $\boldsymbol{D}$, Comparison of the mean voltage-current relationship before and after $5 \mathrm{nM} \mathrm{ATX-II.} \mathrm{Steady-state} \mathrm{voltage} \mathrm{measured} 10 \mathrm{~ms}$ from the end of 800 -ms current injections applied in 20-pA increments from a holding potential of $-93 \mathrm{mV}$. ATX-II induced a significant depolarization of the membrane potential for current steps $>200 \mathrm{pA}(* p<0.05 ; n=9)$.

The ability of P21 SGNs to generate larger currents in response to the repetitive command spikes suggested a decreased refractoriness, possibly enabled by $I_{\mathrm{NaR}}$ flowing through the pool of noninactivated channels between command spikes (Bean, 2007). To examine the currents flowing during the repolarization phase more closely, the action potential clamp was applied to P21 SGNs before and after bath application of 5 nM ATX-II (Fig. 7C). Consistent with our previous observations of the lack of an effect of ATX-II on $I_{\mathrm{NaT}}$ maximum amplitude, there was no appreciable effect on the amplitude of the inward current response coinciding with the first depolarizing phase of the command wave form, but in the presence of ATX-II there were larger currents elicited by the depolarization phase of the subsequent command spikes. This suggests that the P21 SGNs were more able to respond to repetitive stimuli once $I_{\mathrm{NaP}}$ and/or $I_{\mathrm{NaR}}$ were augmented by ATX-II. Importantly, ATX-II also enhanced the separate inward currents that flowed during the repolarization phases of the command action potentials (Fig. 7C, discontinuous gray lines). In all cases, these inward currents were larger following drug exposure. Together, these results suggest that $I_{\mathrm{NaP}}$ and $\mathrm{I}_{\mathrm{NaR}}$ are activated during action potentials in SGNs, and that this raises the likelihood of rapid firing in the auditory nerve.

To examine the effects of ATX-II on excitability and firing behavior, current clamp experiments were conducted on SGNs cultured from hearing mice (P12-P14; Figs. 8, 9). Bath application of ATX-II had the effects of increasing membrane excitability and decreasing the membrane resistance, observations consistent with the potentiation of $I_{\mathrm{NaP}}$ and $I_{\mathrm{NaR}}$. A subset of SGNs display rapidly-adapting behavior in response to square-wave current injections in various preparations under control conditions, generating only a few action potentials at the beginning of the stimulus (Santos-Sacchi, 1993; Jagger and Housley, 2002; Szabó et al., 2002; Jagger and Housley, 2003; Rutherford et al., 2012; Crozier and Davis, 2014; Ballestero et al., 2015; Smith et al., 2015). In rapidlyadapting SGNs, following bath application of $5 \mathrm{nM}$ ATX-II additional action potentials were elicited during the current injection (Fig. 8A-C). In 4/9 rapidly-adapting SGNs, ATX-II had the effect of changing the firing behavior into a nonadapting response (Fig. 8B). The application of ATX-II resulted in a significant increase in the median action potential number (Fig. 8C, paired Wilcoxon signed rank test, $z=-2.46, p=0.0078, n=9$ ). ATX-II significantly increased the steady-state voltage in response to current injection (Fig. 8D; Bonferroni-adjusted paired $t$ test; current step $220 \mathrm{pA} p=0.042 ; 240 \mathrm{pA} p=0.032 ; 260 \mathrm{pA} p$ $=0.027 ; 280 \mathrm{pA} p=0.018)$. Together, these effects of ATX-II further support the hypothesis that $I_{\mathrm{NaR}}$ and $I_{\mathrm{NaP}}$ can increase the excitability of rapidly-adapting SGNs.

Some SGNs cultured from hearing mice respond to maintained depolarizing inputs with a nonadapting response, and some of these cells fire spontaneously at their resting potential (Wang et al., 2013; Smith et al., 2015). These nonadapting SGNs generally have a lower amount of LVA $\mathrm{K}^{+}$current compared to their rapidlyadapting counterparts. We used ATX-II to examine the 

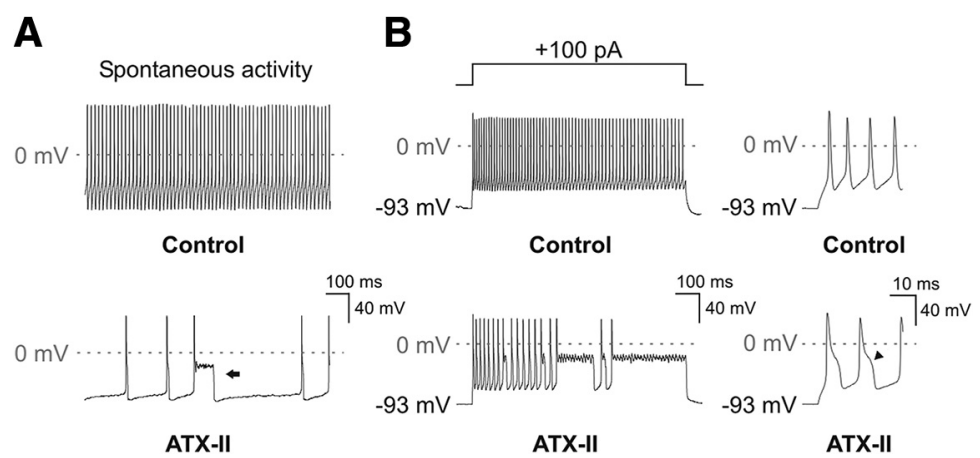

Figure 9. ATX-II induces metastable episodes of the membrane potential and broadens action potentials in nonadapting SGNs. $\boldsymbol{A}$, During a current clamp recording under control conditions (upper panel), a P14 SGN generated action potentials spontaneously without current injection. Following the bath application of 5 nM ATX-II (lower panel), the SGN adopted a slower spontaneous firing behavior, with broader action potentials interspersed with long-lasting depolarizing events (arrow). $\boldsymbol{B}$, In the same SGN, a depolarizing current injection (shown in upper left panel) activated a nonadapting response (middle left panel). After application of $5 \mathrm{nM}$ ATX-II, the repetitive action potentials became interspersed by metastable events of variable lengths (lower left panel). Individual action potentials became broader after ATX-II (lower right panel), each with a short-lasting shoulder during the repolarization phase (arrowheads).

effects of maximizing $I_{\mathrm{NaR}}$ and $I_{\mathrm{NaP}}$ on the distinctive firing behavior of these neurons. In SGNs that fired spontaneously at their resting potential under control conditions (Fig. 9A, upper panel), bath application of 5 nM ATX-II had the unexpected effect of slowing the spontaneous activity (Fig. 9A, lower panel; control $65 \mathrm{~Hz}$, ATX-II $8 \mathrm{~Hz}$, measured in the amplifier's $I=0$ mode). Following ATX-II application, occasional action potentials triggered longlasting depolarizing shifts of the membrane potential that typically lasted 50-100 ms, and these shifts had the effect of preventing regenerative firing. These depolarizing episodes resembled a "metastable condition" induced by ATX-II in regular spiking neocortical pyramidal neurons (Mantegazza et al., 1998), a phenomenon ascribed to the maximal activation of $I_{\mathrm{NaP}}$.

In nonadapting SGNs under control conditions, depolarizing current injections activated trains of regularly shaped action potentials (Fig. 9B, upper panel). Bath application of $5 \mathrm{nM}$ ATX-II again slowed the firing rate during these evoked responses (Fig. 9B, lower panel; control $80 \mathrm{~Hz}$, ATX-II $40 \mathrm{~Hz}$, measured during a +100 pA current injection in current clamp mode), and also resulted in metastable episodes (4/4 nonadapting SGNs). As before, these events had the effect of preventing regenerative firing. Close examination revealed a broadening of individual action potentials following ATX-II application, with the introduction of a distinct short-lasting shoulder during the repolarization phase (Fig. 9B, lower right panel).

\section{Discussion}

This study resulted from the serendipitous observation of $I_{\mathrm{NaP}}$ in SGNs, a depolarization-activated inward current that would ordinarily be masked by an LVA $I_{K}$ (Smith et al., 2015). Further investigation identified another TTXsensitive $\mathrm{Na}^{+}$current, namely $I_{\mathrm{NaR}}$. To our knowledge this is the first description of these nonclassical $\mathrm{Na}^{+}$currents in the mammalian auditory periphery. The unusual conditions required to reveal $I_{\mathrm{NaP}}$ and $\mathrm{I}_{\mathrm{NaR}}$ may explain why they have evaded previous description in SGNs. LVA $I_{K}, I_{\mathrm{Ca}}$, and $I_{h}$ must all be blocked, as they activate over the same voltage range as $I_{\mathrm{Nap}}$. Similarly, $I_{\mathrm{NaR}}$ is only revealed during repolarizing pulses after strong depolarization, at membrane potentials where HVA $I_{K}$ activates. Furthermore, the late appearance of these currents during auditory development means they would not be observed in recordings from neonatal SGNs. We predict that under normal circumstances (1) small depolarizations of the first heminode would activate the noninactivating subthreshold $I_{\mathrm{NaP}}$ which would bring the local membrane potential nearer to its threshold for firing and so increase the effectiveness of subsequent inputs, and (2) the open channel block mediated by Nav $\beta 4$ subunits would increase the number of noninactivated $\mathrm{Na}^{+}$channels, allowing $I_{\mathrm{NaR}}$ to flow during the repolarization phase. This would prevent a deep hyperpolarization between action potentials, thus supporting the generation of a new spike and enabling high-frequency firing.

\section{Persistent and resurgent $\mathrm{Na}^{+}$currents in cultured SGNs}

For this study we employed a preparation of dissociated SGNs from the cochleae of mice, from the early postnatal period until around three months of age. This approach has been used widely over a number of years, and has led to the discovery of numerous ion channel mechanisms that have enhanced our fundamental understanding of auditory coding in the mature cochlea (Rusznák and Szucs, 2009). This preparation has several advantages, including the ease of access to the neuronal soma which can only occur following the retraction of endogenous glia and myelin in vitro, and the ability to record from adult neurons which is precluded in slice preparations by the advance of ossification (Jagger and Housley, 2003). However, both the potential damage induced by the process of dissociation and the artificial conditions imposed on neurons in culture must be considered when interpreting any findings. Survival rates of SGNs may be low (Vieira et al., 2007), with the remaining cells representing only a subpopulation which might influence the conclusions drawn. There is evidence that time in culture can affect ion channel expression and the re- 
sulting firing characteristics of inner ear ganglion neurons (Liu et al., 2016; Cai et al., 2017). It is important therefore, that combinations of techniques are used to qualify observed electrophysiological mechanisms, such as confirmation of ion channel expression and localization using antibody detection methods.

Our experiments using SGNs cultured from hearing mice revealed $I_{\mathrm{NaP}}$ as a sustained inward current elicited during depolarizing voltage ramps or voltage steps. Our data suggest $I_{\mathrm{NaP}}$ has a hyperpolarized activation compared to that of the classical $I_{\mathrm{NaT}}$. The steady-state activation curve for the noninactivating $\mathrm{Na}^{+}$conductance $\left(\mathrm{G}_{\mathrm{NaP}}\right)$ was half activated around $-55 \mathrm{mV}$, which is comparable to values determined in neurons from the hippocampus (French et al., 1990) and sensorimotor cortex (Brown et al., 1994). A persistent current has been described previously in SGNs acutely dissociated from guinea pigs (Santos-Sacchi, 1993). This noninactivating "slow inward current" activated around $-70 \mathrm{mV}$ and was also TTX-sensitive, but it had a reversal potential that suggested it was mediated by multiple ionic species. It was blocked by $50 \mu \mathrm{M} \mathrm{Cd}^{2+}$, a concentration below that used here in our $\mathrm{Na}^{+}$current isolation solution $(300 \mu \mathrm{M})$. The relationship between the current in guinea pig SGNs and the $I_{\mathrm{NaP}}$ we have described in mouse SGNs may require further study.

Voltage step or action potential clamp paradigms revealed $I_{\mathrm{NaR}}$ as an inward current activating during repolarization following strong depolarization. The activation voltage and kinetics of $\mathrm{I}_{\mathrm{NaR}}$ were comparable to those described first in cerebellar Purkinje neurons (Raman and Bean, 1997). These characteristics support the hypothesis that $I_{\mathrm{NaR}}$ acts to minimize the refractory period, when channels mediating $I_{\mathrm{NaT}}$ would otherwise be inactivated. Evidence suggests that the requisite channel subunits for $I_{\mathrm{NaR}}$ are present in SGNs. The effects of a Nav1.6-specific toxin, and the localization of Nav1.6 immunofluorescence seen here and by others (Hossain et al., 2005; Kim and Rutherford, 2016), suggest that this subunit may mediate all three currents. Nav1.1 subunits, which can mediate $I_{\mathrm{NaR}}$ under certain circumstances (Lewis and Raman, 2014), have been detected within the first heminode of SGNs in the rat cochlea, although not within their nodes of Ranvier (Kim and Rutherford, 2016). Localization of Nav $\beta 4$ subunits within the spike generator region and nodes of Ranvier in the spiral ganglion are consistent with models for $I_{\mathrm{NaR}}$ in other fast-spiking neurons (Cruz et al., 2011; Theile and Cummins, 2011; Lewis and Raman, 2014).

The effects of ATX-II on $I_{\mathrm{NaP}}$ and $I_{\mathrm{NaR}}$, and the resulting changes of SGN firing properties were reminiscent of those seen in other neuronal types (Mantegazza et al., 1998; Brand et al., 2000; Klinger et al., 2012). This further suggests that the currents we identified in SGNs share a common biophysical basis with $I_{\mathrm{NaP}}$ and $I_{\mathrm{NaR}}$ described elsewhere. Maximal enhancements of $I_{\mathrm{NaP}}$ and $I_{\mathrm{NaR}}$ had differential effects on the excitability of rapidly-adapting and nonadapting SGNs. Rapid adaptation in SGNs has been linked to the expression of activated Kv1-type channels, which prevent repetitive firing during sustained current injections (Szabó et al., 2002; Wang et al., 2013;
Crozier and Davis, 2014; Smith et al., 2015). Application of ATX-II to rapidly-adapting cells was associated with an increased likelihood of firing additional action potentials, suggesting that the depolarizing effect of maximally enhancing $I_{\mathrm{NaP}}$ and $\mathrm{I}_{\mathrm{NaR}}$ was sufficient to overcome the inhibitory influence of the Kv1-mediated currents. In the nonadapting cells, which have minimal Kv1-mediated currents, ATX-II had the effect of broadening action potentials and even inducing metastable depolarizations. This resembled the effects of ATX-II via increased $I_{\mathrm{NaP}}$ in neocortical pyramidal neurons (Mantegazza et al., 1998), and the sustained depolarizations probably reflect a lack of sufficient repolarization by $\mathrm{K}^{+}$channels. Future studies should determine how $I_{\mathrm{NaP}}$ and $I_{\mathrm{NaR}}$ contribute to SGN responses during more physiologic stimuli, preferably in intact cochlear preparations.

\section{Rapid spiking behavior in the auditory pathway}

SGNs in the auditory nerve are among the fastest spiking single units in the nervous system (Heil and Peterson, 2015). They are able to achieve a high temporal precision which preserves the auditory code generated by the presynaptic specializations of IHCs (Rutherford et al., 2012). It is perhaps not surprising, therefore, that SGNs employ mechanisms common to other fast-spiking neurons. By providing subthreshold depolarizing drive (in the case of $I_{\mathrm{NaP}}$ ), or by ensuring there are pools of noninactivated $\mathrm{Na}^{+}$ channels available immediately following action potential depolarization (in the case of $I_{\mathrm{NaR}}$ ), these currents may contribute to the regulation of spontaneous and evoked firing rates in the auditory periphery. $I_{\mathrm{NaP}}$ and $I_{\mathrm{NaR}}$ have been observed in the medial nucleus of the trapezoid body (Leão et al., 2006; Huang and Trussell, 2008; Kim et al., 2010; Berret et al., 2016), an auditory center renowned for its preservation of temporal fidelity. Also, $I_{\mathrm{NaP}}$ supports burst firing in primary afferents of the goldfish sacculus, which in turn amplifies resonance in their target Mauthner neurons (Curti et al., 2008).

Spontaneous activity may contribute to the development of normal mammalian hearing. Hearing onset in altricial mammals such as cats and rodents occurs during the second postnatal week. Before this, low-frequency spontaneous firing rates (SFRs, typically $<5$ spikes/s) are seen in auditory nerve recordings from postnatal kittens (Jones et al., 2007), and in loose patch recordings from rat SGNs in cochlear explants (Tritsch and Bergles, 2010). This spontaneous activity may contribute to the establishment of tonotopic maps in the auditory brain (Jones et al., 2007). A recent in vitro study reported that just after hearing onset in rats (P15-P17), SGNs have SFRs ranging from $0-16$ spikes/s (Wu et al., 2016). This range diversifies rapidly over the following weeks (P19-P21, 0-44 spikes/s; P29-P32, 0-55 spikes/s), and refractory periods shorten accordingly. Our observation of increasing $I_{\mathrm{NaP}}$ and $I_{\mathrm{NaR}}$ during this period may help to explain these changes. As there were no obvious regional differences in $I_{\mathrm{NaP}}$ and $I_{\mathrm{NaP}}$ in the SGNs cultured from animals aged P21 and older, we suggest that those observed in the younger animals were purely developmental, and reflected a progressive maturation of cell properties (including concomitant in- 
creases of $\mathrm{K}^{+}$current amplitudes) from the cochlear base toward the apex.

The rapid spontaneous and evoked spiking observed in mature SGNs points to tightly controlled refractoriness. For type I afferents, the mean absolute refractory period (during which no second spike can be evoked) has been measured as $0.33 \mathrm{~ms}$, and the time constant of the mean relative refractory period (during which the probability of a spike increases with time, or the stimulus strength required to trigger a spike with a given probability decreases with time) has been measured as $0.41 \mathrm{~ms}$ (Miller et al., 2001), which are brief even in comparison to rapidspiking neurons such as cerebellar Purkinje neurons (Khaliq and Raman, 2005). In the auditory nerve there is a high density of Nav channel subunits at the first heminode, the site of spike initiation, and also at nodes of Ranvier (Hossain et al., 2005; Smith et al., 2015; Kim and Rutherford, 2016). This organization first appears between P5-P7 in rats (Kim and Rutherford, 2016), coinciding with increased maximal firing rates (Tritsch and Bergles, 2010). This period is roughly equivalent to that in mice, when we first observed $\mathrm{I}_{\mathrm{NaP}}$ and $\mathrm{I}_{\mathrm{NaR}}$. By P20-P21, in the rat, there is coexpression of Nav1.1 and Nav1.6 channels at the first heminode, which can both mediate $\mathrm{I}_{\mathrm{NaR}}$, but only Nav1.6 is detected at subsequent nodes of Ranvier (Kim and Rutherford, 2016). In the young adult mouse there is a comparable distribution of Nav1.6 immunofluorescence, as shown here and elsewhere (Hossain et al., 2005), and this pattern resembles that of Kv3.1b subunits (Smith et al., 2015), whose activation and deactivation kinetics enable the ultra-rapid repolarization essential for repetitive firing. Together, these observations suggest the existence of mechanisms ensuring rapid recovery from action potential firing in SGNs.

\section{Persistent and resurgent $\mathrm{Na}^{+}$currents in health and disease}

There is an increasing appreciation of how $I_{\mathrm{NaP}}$ and $\mathrm{I}_{\mathrm{NaR}}$ contribute to normal spontaneous and evoked firing. $I_{\mathrm{NaP}}$ typically activates at subthreshold membrane potentials, a characteristic that implicates it in boosting distal synaptic potentials to reach the soma (Crill, 1996), and in repetitive action potential generation at the axon initial segment (Osorio et al., 2010). $\mathrm{I}_{\mathrm{NaR}}$ contributes to normal function in $\sim 20$ neuronal types, the best studied of these being cerebellar Purkinje neurons (Raman and Bean, 1997; Raman et al., 1997; Grieco et al., 2005; Akemann and Knöpfel, 2006; Yan et al., 2014; Ransdell et al., 2017). These inhibitory neurons have SFRs of $\sim 30-50$ spikes/s and can support evoked firing up to $\sim 250$ spikes/s. This ability is attributed to $\mathrm{I}_{\mathrm{NaR}}$ mediated via Nav1.6/Nav $\beta 4$ channels localized at the axon initial segment. In Purkinje neurons, the rapid repolarizing action of Kv3 channels complements the function of $\mathrm{I}_{\mathrm{NaR}}$ (Akemann and Knöpfel, 2006), in a manner comparable to that we propose here for SGNs.

Nav1.6 subunits underlie $\mathrm{I}_{\mathrm{NaP}}$ and $\mathrm{I}_{\mathrm{NaR}}$ in various neuronal types, and alterations of Nav1.6 expression or gating characteristics result in disease phenotypes. In Nav1.6-null mice, $I_{\mathrm{NaP}}$ is down-regulated in cerebellar
Purkinje neurons (Raman et al., 1997; Grieco and Raman, 2004), cortical pyramidal neurons (Maurice et al., 2001) and cerebellar granule cells (Osorio et al., 2010). There is a $90 \%$ decrease of $\mathrm{I}_{\mathrm{NaR}}$ in Purkinje cells of Nav1.6-null mice (Raman and Bean, 1997), suggesting that this subunit underlies the majority of the endogenous current. Both $I_{\mathrm{NaP}}$ and $\mathrm{I}_{\mathrm{NaR}}$ have been implicated in disease pathologies related to altered cellular excitability (Cruz et al., 2011; Theile and Cummins, 2011; O'Brien and Meisler, 2013; Lewis and Raman, 2014). Studies of epilepsy models suggest that alterations of Nav1.6 subunit gating lead to enhanced $I_{\mathrm{NaR}}$, resulting in neuronal hyperexcitability and epileptogenesis (Hargus et al., 2013). In dorsal root ganglion neurons the chemotherapy drug oxaliplatin slows inactivation of Nav1.6, which enhances $I_{\mathrm{NaP}}$ and $\mathrm{I}_{\mathrm{NaR}}$, and may cause acute cooling-aggravated neuropathy (Sittl et al., 2012).

Mice with a targeted deletion of Nav $\beta 4$ in the cerebellum display motor control deficits, and their Purkinje neurons have reduced spontaneous and evoked firing rates (Ransdell et al., 2017). However, the amplitude of $\mathrm{I}_{\mathrm{NaR}}$ reduces by only $\sim 50 \%$ in this model, suggesting that although $\mathrm{Nav} \beta 4$ contributes to $\mathrm{I}_{\mathrm{NaR}}$ generation additional mechanisms may be required. $I_{\mathrm{NaP}}$ and $\mathrm{I}_{\mathrm{NaR}}$ amplitudes can be decreased by RNA interference techniques (Bant and Raman, 2010; Xie et al., 2013; Yan et al., 2014; Ransdell et al., 2017), suggesting that specific in vivo targeting of the channels mediating these currents is a viable therapeutic option for conditions of neuronal hyperexcitability. Accordingly, these channel subunits may represent novel targets for treating neuropathies in the auditory periphery. Future studies should further delineate their contribution to normal hearing, and identify how each current has site-specific actions contributing to fast spiking in the mature auditory nerve.

\section{References}

Akemann W, Knöpfel T (2006) Interaction of Kv3 potassium channels and resurgent sodium current influences the rate of spontaneous firing of Purkinje neurons. J Neurosci 26:4602-4612. CrossRef Medline

Ballestero J, Recugnat M, Laudanski J, Smith KE, Jagger DJ, Gnansia D, McAlpine D (2015) Reducing current spread by use of a novel pulse shape for electrical stimulation of the auditory nerve. Trends Hear 19. CrossRef

Bant JS, Raman IM (2010) Control of transient, resurgent, and persistent current by open-channel block by $\mathrm{Na}$ channel beta4 in cultured cerebellar granule neurons. Proc Natl Acad Sci USA 107:12357-12362. CrossRef Medline

Bean BP (2007) The action potential in mammalian central neurons. Nat Rev Neurosci 8:451-465. CrossRef Medline

Berret E, Kim SE, Lee SY, Kushmerick C, Kim JH (2016) Functional and structural properties of ion channels at the nerve terminal depends on compact myelin. J Physiol 594:5593-5609. CrossRef Medline

Brand S, Seeger T, Alzheimer C (2000) Enhancement of persistent $\mathrm{Na}+$ current by sea anemone toxin (ATX II) exerts dual action on hippocampal excitability. Eur J Neurosci 12:2387-2396. Medline

Brown AM, Schwindt PC, Crill WE (1994) Different voltage dependence of transient and persistent $\mathrm{Na}+$ currents is compatible with modal-gating hypothesis for sodium channels. J Neurophysiol 71:2562-2565. Medline 
Buffington SA, Rasband MN (2013) Na+ channel-dependent recruitment of $\mathrm{Nav} \beta 4$ to axon initial segments and nodes of Ranvier. J Neurosci 33:6191-6202. CrossRef Medline

Cai HQ, Gillespie LN, Wright T, Brown WGA, Minter R, Nayagam BA, O'Leary SJ, Needham K (2017) Time-dependent activity of primary auditory neurons in the presence of neurotrophins and antibiotics. Hear Res 350:122-132. CrossRef Medline

Crill WE (1996) Persistent sodium current in mammalian central neurons. Annu Rev Physiol 58:349-362. CrossRef Medline

Crozier RA, Davis RL (2014) Unmasking of spiral ganglion neuron firing dynamics by membrane potential and neurotrophin-3. J Neurosci 34:9688-9702. CrossRef Medline

Cruz JS, Silva DF, Ribeiro LA, Araujo IG, Magalhães N, Medeiros A, Freitas C, Araujo IC, Oliveira FA (2011) Resurgent $\mathrm{Na}+$ current: a new avenue to neuronal excitability control. Life Sci 89:564-569. CrossRef Medline

Curti S, Gómez L, Budelli R, Pereda AE (2008) Subthreshold sodium current underlies essential functional specializations at primary auditory afferents. J Neurophysiol 99:1683-1699. CrossRef Medline

French CR, Sah P, Buckett KJ, Gage PW (1990) A voltagedependent persistent sodium current in mammalian hippocampal neurons. J Gen Physiol 95:1139-1157. Medline

Fryatt AG, Vial C, Mulheran M, Gunthorpe MJ, Grubb BD (2009) Voltage-gated sodium channel expression in rat spiral ganglion neurons. Mol Cell Neurosci 42:399-407. CrossRef Medline

Grieco TM, Raman IM (2004) Production of resurgent current in NaV1.6-null Purkinje neurons by slowing sodium channel inactivation with beta-pompilidotoxin. J Neurosci 24:35-42. CrossRef Medline

Grieco TM, Malhotra JD, Chen C, Isom LL, Raman IM (2005) Openchannel block by the cytoplasmic tail of sodium channel beta4 as a mechanism for resurgent sodium current. Neuron 45:233-244. CrossRef Medline

Hargus NJ, Nigam A, Bertram EH 3rd, Patel MK (2013) Evidence for a role of Nav1.6 in facilitating increases in neuronal hyperexcitability during epileptogenesis. J Neurophysiol 110:1144-1157. CrossRef

Heil P, Peterson AJ (2015) Basic response properties of auditory nerve fibers: a review. Cell Tissue Res 361:129-158. CrossRef Medline

Hossain WA, Antic SD, Yang Y, Rasband MN, Morest DK (2005) Where is the spike generator of the cochlear nerve? Voltage-gated sodium channels in the mouse cochlea. J Neurosci 25:6857-6868. CrossRef Medline

Huang H, Trussell LO (2008) Control of presynaptic function by a persistent $\mathrm{Na}(+)$ current. Neuron 60:975-979. CrossRef Medline

Jagger DJ, Housley GD (2002) A-type potassium currents dominate repolarisation of neonatal rat primary auditory neurones in situ. Neuroscience 109:169-182. Medline

Jagger DJ, Housley GD (2003) Membrane properties of type II spiral ganglion neurones identified in a neonatal rat cochlear slice. $J$ Physiol 552:525-533. CrossRef

Jones TA, Leake PA, Snyder RL, Stakhovskaya O, Bonham B (2007) Spontaneous discharge patterns in cochlear spiral ganglion cells before the onset of hearing in cats. J Neurophysiol 98:1898-1908. CrossRef

Khaliq ZM, Raman IM (2005) Axonal propagation of simple and complex spikes in cerebellar Purkinje neurons. J Neurosci 25:454463. CrossRef Medline

Kim JH, Kushmerick C, von Gersdorff H (2010) Presynaptic resurgent $\mathrm{Na}+$ currents sculpt the action potential waveform and increase firing reliability at a CNS nerve terminal. J Neurosci 30:1547915490. CrossRef

Kim KX, Rutherford MA (2016) Maturation of NaV and KV channel topographies in the auditory nerve spike initiator before and after developmental onset of hearing function. J Neurosci 36:21112118. CrossRef Medline

Klinger AB, Eberhardt M, Link AS, Namer B, Kutsche LK, Schuy ET, Sittl R, Hoffmann T, Alzheimer C, Huth T, Carr RW, Lampert A
(2012) Sea-anemone toxin ATX-II elicits A-fiber-dependent pain and enhances resurgent and persistent sodium currents in large sensory neurons. Mol Pain 8:69. CrossRef Medline

Leão RN, Naves MM, Leão KE, Walmsley B (2006) Altered sodium currents in auditory neurons of congenitally deaf mice. Eur $\mathrm{J}$ Neurosci 24:1137-1146. CrossRef Medline

Lewis AH, Raman IM (2014) Resurgent current of voltage-gated $\mathrm{Na}(+)$ channels. J Physiol 592:4825-4838. CrossRef Medline

Liu XP, Wooltorton JR, Gaboyard-Niay S, Yang FC, Lysakowski A, Eatock RA (2016) Sodium channel diversity in the vestibular ganglion: NaV1.5, NaV1.8, and tetrodotoxin-sensitive currents. J Neurophysiol 115:2536-2555. CrossRef Medline

Mann ZF, Kelley MW (2011) Development of tonotopy in the auditory periphery. Hear Res 276:2-15. CrossRef Medline

Mantegazza M, Franceschetti S, Avanzini G (1998) Anemone toxin (ATX II)-induced increase in persistent sodium current: effects on the firing properties of rat neocortical pyramidal neurones. J Physiol 507:105-116. CrossRef

Maurice N, Tkatch T, Meisler M, Sprunger LK, Surmeier DJ (2001) D1/D5 dopamine receptor activation differentially modulates rapidly inactivating and persistent sodium currents in prefrontal cortex pyramidal neurons. J Neurosci 21:2268-2277. Medline

Meyer AC, Moser T (2010) Structure and function of cochlear afferent innervation. Curr Opin Otolaryngol Head Neck Surg 18:441-446. CrossRef Medline

Miller CA, Abbas PJ, Robinson BK (2001) Response properties of the refractory auditory nerve fiber. J Assoc Res Otolaryngol 2:216232. Medline

Nayagam BA, Muniak MA, Ryugo DK (2011) The spiral ganglion: connecting the peripheral and central auditory systems. Hear Res 278:2-20. CrossRef Medline

O'Brien JE, Meisler MH (2013) Sodium channel SCN8A (Nav1.6): properties and de novo mutations in epileptic encephalopathy and intellectual disability. Front Genet 4:213.

Osorio N, Cathala L, Meisler MH, Crest M, Magistretti J, Delmas P (2010) Persistent Nav1.6 current at axon initial segments tunes spike timing of cerebellar granule cells. J Physiol 588:651-670. CrossRef

Raman IM, Bean BP (1997) Resurgent sodium current and action potential formation in dissociated cerebellar Purkinje neurons. $J$ Neurosci 17:4517-4526. Medline

Raman IM, Sprunger LK, Meisler MH, Bean BP (1997) Altered subthreshold sodium currents and disrupted firing patterns in Purkinje neurons of Scn8a mutant mice. Neuron. 19:881-891. CrossRef

Ransdell JL, Dranoff E, Lau B, Lo WL, Donermeyer DL, Allen PM, Nerbonne JM (2017) Loss of Nav $\beta 4$-mediated regulation of sodium currents in adult Purkinje neurons disrupts firing and impairs motor coordination and balance. Cell Rep 19:532-544. CrossRef

Rosker C, Lohberger B, Hofer D, Steinecker B, Quasthoff S, Schreibmayer W (2007) The TTX metabolite 4,9-anhydro-TTX is a highly specific blocker of the $\mathrm{Na}(\mathrm{v} 1.6)$ voltage-dependent sodium channel. Am J Physiol Cell Physiol 293:C783-C789. CrossRef Medline

Rusznák Z, Szucs G (2009) Spiral ganglion neurones: an overview of morphology, firing behaviour, ionic channels and function. Pflugers Arch 457:1303-1325. CrossRef Medline

Rutherford MA, Chapochnikov NM, Moser T (2012) Spike encoding of neurotransmitter release timing by spiral ganglion neurons of the cochlea. J Neurosci 32:4773-4789. CrossRef Medline

Santos-Sacchi J (1993) Voltage-dependent ionic conductances of type I spiral ganglion cells from the guinea pig inner ear. J Neurosci 13:3599-3611. Medline

Sittl R, Lampert A, Huth T, Schuy ET, Link AS, Fleckenstein J, Alzheimer C, Grafe P, Carr RW (2012) Anticancer drug oxaliplatin induces acute cooling-aggravated neuropathy via sodium channel subtype $\mathrm{Na}(\mathrm{V}) 1.6-$-resurgent and persistent current. Proc Natl Acad Sci USA 109:6704-6709. CrossRef Medline

Smith KE, Browne L, Selwood DL, McAlpine D, Jagger DJ (2015) Phosphoinositide modulation of heteromeric Kv1 channels adjusts output of spiral ganglion neurons from hearing mice. J Neurosci 35:11221-11232. CrossRef Medline 
Stafstrom CE (2007) Persistent sodium current and its role in epilepsy. Epilepsy Curr 7:15-22. CrossRef Medline

Szabó ZS, Harasztosi CS, Sziklai I, Szûcs G, Rusznák Z (2002) Ionic currents determining the membrane characteristics of type I spiral ganglion neurons of the guinea pig. Eur J Neurosci 16:1887-1895. Medline

Taberner AM, Liberman MC (2005) Response properties of single auditory nerve fibers in the mouse. J Neurophysiol 93:557-569.

Theile JW, Cummins TR (2011) Recent developments regarding voltage-gated sodium channel blockers for the treatment of inherited and acquired neuropathic pain syndromes. Front Pharmacol 2:54. CrossRef Medline

Tritsch NX, Bergles DE (2010) Developmental regulation of spontaneous activity in the mammalian cochlea. J Neurosci 30:15391550. CrossRef Medline

Vieira M, Christensen BL, Wheeler BC, Feng AS, Kollmar R (2007) Survival and stimulation of neurite outgrowth in a serum-free culture of spiral ganglion neurons from adult mice. Hear Res 230:17-23. CrossRef
Wang W, Kim HJ, Lv P, Tempel B, Yamoah EN (2013) Association of the Kv1 family of $\mathrm{K}+$ channels and their functional blueprint in the properties of auditory neurons as revealed by genetic and functional analyses. J Neurophysiol 110:1751-1764. CrossRef Medline Wright T, Gillespie LN, O'Leary SJ, Needham K (2016) Firing frequency and entrainment maintained in primary auditory neurons in the presence of combined BDNF and NT3. Sci Rep 6:28584. CrossRef Medline

Wu JS, Young ED, Glowatzki E (2016) Maturation of spontaneous firing properties after hearing onset in rat auditory nerve fibers: spontaneous rates, refractoriness, and interfiber correlations. J Neurosci 36:10584-10597. CrossRef Medline

Xie W, Strong JA, Ye L, Mao JX, Zhang JM (2013) Knockdown of sodium channel NaV1.6 blocks mechanical pain and abnormal bursting activity of afferent neurons in inflamed sensory ganglia. Pain 154:1170-1180. CrossRef Medline

Yan H, Pablo JL, Wang C, Pitt GS (2014) FGF14 modulates resurgent sodium current in mouse cerebellar Purkinje neurons. Elife 3:e04193. CrossRef Medline 